\title{
Retrieving the vertical distribution of stratospheric OClO from Odin/OSIRIS limb-scattered sunlight measurements
}

\author{
P. Krecl ${ }^{1, *}$, C. S. Haley ${ }^{2}$, J. Stegman ${ }^{1}$, S. M. Brohede ${ }^{3}$, and G. Berthet ${ }^{4, * *}$ \\ ${ }^{1}$ Department of Meteorology, Stockholm University, Stockholm, Sweden \\ ${ }^{2}$ Centre for Research in Earth and Space Science, York University, Toronto, Canada \\ ${ }^{3}$ Department of Radio and Space Science, Chalmers University of Technology, Göteborg, Sweden \\ ${ }^{4}$ Service d'Aéronomie, Institut Pierre-Simon Laplace, Paris, France \\ *now at: Department of Applied Environmental Science, Stockholm University, Stockholm, Sweden \\ ** now at: Department of Applied Mathematics and Theoretical Physics, University of Cambridge, Cambridge, UK
}

Received: 28 February 2005 - Published in Atmos. Chem. Phys. Discuss.: 13 May 2005

Revised: 8 November 2005 - Accepted: 23 January 2006 - Published: 31 May 2006

\begin{abstract}
The first vertical profiles of stratospheric OClO retrieved from Odin/OSIRIS limb-scattered sunlight radiances are presented. The retrieval method is based on a two-step approach, using differential optical absorption spectroscopy combined with the maximum a posteriori estimator. The details of the spectral window selection, spectral corrections and inversion technique are discussed. The results show that OClO can be detected inside the South polar vortex region between about 14 and $22 \mathrm{~km}$ altitude with a $2-5 \mathrm{~km}$ height resolution and an estimated retrieval error better than $50 \%$ at the peak. OClO concentrations show the expected relation to the atmospheric conditions in the lower stratosphere in the austral spring 2002. This unique data set of OClO profiles is very promising to study the stratospheric chlorine activation in both polar regions.
\end{abstract}

\section{Introduction}

Since the dramatic ozone destruction over Antarctica was discovered by Farman et al. (1985), laboratory and model studies in combination with stratospheric observations have improved the scientific understanding of the complex and interactive processes behind this annual depletion (review of historical research in Solomon, 1999). Moreover, these studies have revealed that a less severe stratospheric ozone loss occurs over the Arctic region during springtime (WMO, 2003). Stratospheric ozone is destroyed in the polar re-

Correspondence to: P. Krecl

(patricia.krecl@itm.su.se) gions by several catalytic cycles involving reactive halogen species, primarily chlorine and bromine. Polar stratospheric clouds (PSCs), which are formed during the cold and dark winter, play a crucial role in the so-called chlorine activation. This activation refers to the conversion of chlorine reservoir gases (including $\mathrm{HCl}$ and $\mathrm{ClONO}_{2}$ ) into the more reactive forms $(\mathrm{ClO}$ and $\mathrm{ClOOCl})$ by heterogeneous reactions occurring on the surface of the PSC particles. One of the consequences of the chlorine activation is the formation of chlorine dioxide $(\mathrm{OClO})$ mainly by the reaction

$\mathrm{ClO}+\mathrm{BrO} \longrightarrow \mathrm{OClO}+\mathrm{Br}$,

that occurs in the lower stratosphere. $\mathrm{OClO}$ is rapidly photolyzed producing $\mathrm{ClO}$ and $\mathrm{O}$,

$\mathrm{OClO}+h v \longrightarrow \mathrm{ClO}+\mathrm{O}$,

leading to a null cycle when atomic oxygen combines with molecular oxygen to reform ozone. Even though $\mathrm{OClO}$ is not directly involved in the ozone destruction, its concentration is a quantitative indicator of the degree of chlorine activation at solar zenith angles (SZA) smaller than $92^{\circ}$ (Sessler et al., 1995).

The presence of $\mathrm{OClO}$ in the atmosphere was first detected at McMurdo Station (Antarctica) by Solomon et al. (1987) during the austral spring in 1986. Since then, total column densities of $\mathrm{OClO}$ have been derived from groundbased, airborne, and satellite measurements in the Arctic and Antarctic regions (e.g., Sanders et al., 1989; Schiller et al., 1990; Perner et al., 1991; Brandtjen et al., 1994; Wagner et al., 2001). Though measurements of OClO total column

Published by Copernicus GmbH on behalf of the European Geosciences Union. 
amounts are important, the $\mathrm{OClO}$ vertical distribution is required to increase the confidence in the assumed relationship between the stratospheric levels of $\mathrm{BrO}$ and $\mathrm{OClO}$ in model calculations and thereby to improve the model computations of the ozone destruction. It is also important to increase the confidence in the assumed relation between the stratospheric levels of $\mathrm{BrO}$ and $\mathrm{OClO}$ in the model calculations. Despite the relevance of these profiles, OClO vertical concentrations have been only measured in a few balloon campaigns in northern Scandinavia (e.g., Pommereau and Piquard, 1994; Renard et al., 1997; Payan et al., 1999; Rivière et al., 2003).

The need for global coverage and high vertical resolution of atmospheric information led to the development of the atmospheric limb-scattering technique. In this complex viewing geometry, sunlight scattered from the Earth's limb is measured on the sunlit atmosphere at different tangent heights. Some recently launched satellite instruments measure limb-scattered radiances with the objective of retrieving the vertical distribution of trace gases, including OClO. The Optical Spectrograph and InfraRed Imager System (OSIRIS) onboard the Odin satellite (Llewellyn et al., 2004) and the Scanning Imaging Absorption spectroMeter for Atmospheric CHartographY (SCIAMACHY) on the ENVISAT spacecraft (Bovensmann et al., 1999) were specially designed to measure limb-scattered sunlight radiances with a near-global coverage and high vertical resolution (1-3 km). Two other instruments, the Global Ozone Monitoring by Occultation of Stars (GOMOS) also onboard ENVISAT (Bertaux et al., 1991) and the Stratospheric Aerosol and Gas Experiment III (SAGE III) on the Meteor-3M platform (McCormick et al., 1991), are primarily occultation instruments, but also have a limb-scatter measurement capability.

This paper reports the first OClO number density profiles retrieved from OSIRIS limb-scattered radiances using differential optical absorption spectroscopy (DOAS) (Platt, 1994) combined with an optimal estimation (OE) method, more specifically the maximum a posteriori (MAP) estimator (Rodgers, 2000). After a summary of OSIRIS and Odin characteristics is given, the retrieval algorithm is described together with some sensitivity studies of the calculated $\mathrm{OClO}$ effective column densities (ECD). OSIRIS OClO profiles are then compared with some balloon measurements performed in the past. Results for high chlorine activation conditions in the austral spring 2002 are presented together with an outlook on the future work to be done.

\section{OSIRIS instrument}

The Odin satellite has a joint aeronomy and astronomy mission (Murtagh et al., 2002), sharing the main instrument which is an advanced Submillimetre and Millimetre Radiometer (SMR) (Frisk et al., 2003). For the aeronomy mission, the payload is complemented by another passive re- mote sensing instrument, OSIRIS (Llewellyn et al., 2004). Odin was launched in February 2001 into a $600 \mathrm{~km}$ circular Sun-synchronous near terminator orbit with the ascending node at 18:00 local solar time (LST). The coaligned instruments scan the terrestrial limb between 7 and $70 \mathrm{~km}$ tangent height in the stratospheric mode or between 7 and $110 \mathrm{~km}$ for the stratospheric-mesospheric mode at a rate of $0.75 \mathrm{~km} \mathrm{~s}^{-1}$ through nodding of the spacecraft. Odin completes about 15 orbits per day and, when operated in the stratospheric mode, approximately 65 scans are carried out per orbit. The inclination of Odin's orbit is $97.8^{\circ}$, limiting the latitudinal coverage to between $82.2^{\circ} \mathrm{N}$ and $82.2^{\circ} \mathrm{S}$ when viewing in the orbit plane. An off-plane mode is occasionally used to provide better global coverage, for example during the ozone 'hole' period. OSIRIS consists of two optically independent components: the Optical Spectrograph (OS) and the Infrared Imager (IRI). The spectrograph provides a spectral coverage from 280 to $800 \mathrm{~nm}$ with a resolution (full width at half maximum, FWHM) of approximately $1 \mathrm{~nm}$. The instantaneous field of view is $1 \mathrm{~km}$ in the vertical and $40 \mathrm{~km}$ in the horizontal at the tangent point. This study is focused on the OS, since chlorine dioxide absorbs in the ultraviolet (UV) and visible regions.

\section{Methodology}

Several methods have been developed to retrieve vertical profiles of trace gases from limb-scatter measurements (e.g., Aruga and Heath, 1982; Rusch et al., 1984; Flittner et al., 2000; Kaiser, 2001). Within the Odin/OSIRIS team, early studies with simulated spectra were carried out before Odin was launched. McDade et al. (2002) proposed to compute ECD as a function of tangent height by using the DOAS technique, followed by an iterative least squares (ILS) inversion to extract vertical density profiles of $\mathrm{O}_{3}, \mathrm{NO}_{2}, \mathrm{BrO}$, and OClO. The disadvantage of this ILS algorithm is that it does not provide useful statistics on the uncertainties in the solution vector. Alternatively, Strong et al. (2002) described a combined DOAS-OE method to calculate vertical concentration profiles of $\mathrm{O}_{3}, \mathrm{NO}_{2}, \mathrm{BrO}$, and $\mathrm{OClO}$. Based on the approach of Strong et al. (2002), Haley et al. (2004) successfully retrieved stratospheric $\mathrm{O}_{3}$ and $\mathrm{NO}_{2}$ number density profiles from OS limb-scattered sunlight measurements.

In this study, the two-step method presented in Haley et al. (2004) is used to derive OClO vertical number density profiles from OS limb-scattered sunlight measurements in the near-UV and violet regions of the solar spectrum. The first step is the spectral analysis of the OS measurements to calculate the OCIO ECD profiles by applying the DOAS technique. The second step is the inversion of these ECD profiles to obtain the number density profiles using a nonlinear iterative version of the MAP estimator coupled with the LIMBTRAN (Griffioen and Oikarinen, 2000) radiative 
Table 1. Summary of the specifications of the spectral window used to retrieve $\mathrm{OClO}$.

\begin{tabular}{ll}
\hline Wavelengths & $403-427 \mathrm{~nm}$ \\
Fitted species & $\mathrm{OClO}, \mathrm{O}_{3}, \mathrm{NO}_{2}, \mathrm{O}_{4}$ \\
Closure polynomial & 2nd order \\
Spectral corrections & Rayleigh, $I_{o}$, tilt \\
Retrieval range & $10-40 \mathrm{~km}$ \\
Reference spectrum height & $40-70 \mathrm{~km}$ average \\
Estimating K & $2 \lambda, \mathrm{MS}$, no aerosol \\
Estimating $\boldsymbol{F}$ & $2-\mathrm{nm}$ grid \\
A priori STD & $300 \%$ \\
Correlation length & $4 \mathrm{~km}$ \\
\hline
\end{tabular}

transfer model. Table 1 summarizes the specifications of the spectral window used to retrieve $\mathrm{OClO}$ in this work.

\subsection{Spectral analysis}

The effective column densities of the absorbers at each tangent height are calculated by using the well-known DOAS technique (e.g., Noxon, 1975; Noxon et al., 1979; and Platt et al., 1979). A detailed description of DOAS applied to OS scattered sunlight limb radiances can be found in Haley et al. (2004). In this study, the method described by Haley et al. (2004) is used with some modifications outlined in the following sections.

A residual analysis is carried out to assess the adequacy of the fit to the measurements. The fitting residual $r$ is defined as the difference between the differential optical depth (DOD) of the observed and modelled spectra at each tangent height $h_{t}$ and wavelength $\lambda$ :

$r\left(\lambda, h_{t}\right)=\tau_{\mathrm{obs}}^{\prime}\left(\lambda, h_{t}\right)-\sum_{i} \sigma_{i}^{\prime}(\lambda) c_{i}\left(h_{t}\right)$,

where $\tau_{\mathrm{obs}}^{\prime}$ is the observed DOD, $\sigma_{i}^{\prime}(\lambda)$ is the differential absorption cross section of the $i$ th species, and $c_{i}\left(h_{t}\right)$ is the effective column density of the $i$ th species as measured in the direction of the line of sight (LOS). The residual gives a measure of the overall quality of the fit and would consist of only random noise for a perfect model and an ideal measurement. The root mean square (RMS) of the residuals at the tangent height $h_{t}$ is determined by

$r_{\mathrm{RMS}}\left(h_{t}\right)=\sqrt{\frac{\sum_{j=1}^{\eta} r\left(\lambda_{j}, h_{t}\right)^{2}}{\eta}}$,

where $\eta$ is the number of pixels in the fitting region. A chisquared test is also performed to determine if the fit to the DOD is consistent with the measured DOD within the esti-

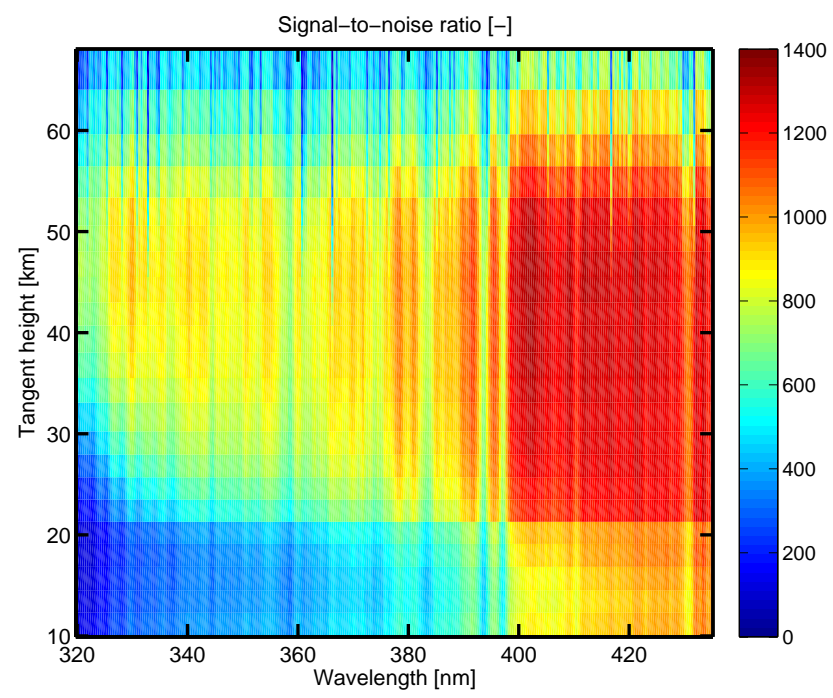

Fig. 1. Limb radiance signal-to-noise ratio as a function of wavelength and tangent height for OS scan 8567046, performed on 19

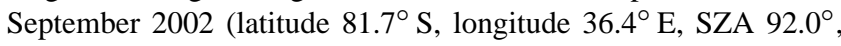
18:10 LST).

mated error of the measurements. The DOAS reduced chisquared statistic $\chi_{\text {doas }}^{2}$ is calculated as

$\chi_{\text {doas }}^{2}\left(h_{t}\right)=\frac{\sum_{j=1}^{\eta}\left[\frac{r\left(\lambda_{j}, h_{t}\right)}{\varepsilon_{\tau_{\mathrm{obs}}^{\prime}}\left(\lambda_{j}, h_{t}\right)}\right]^{2}}{d}$,

where $\varepsilon_{\tau_{\mathrm{obs}}^{\prime}}\left(\lambda_{j}, h_{t}\right)$ is the standard deviation of the error in the observed DOD resulting from OS measurement error, and $d$ is the number of degrees of freedom (i.e., the number of pixels in the spectral window minus the number of parameters used in the fit). The errors in OS observed radiances are estimated considering the photon shot noise from the source, shot noise due to the detector dark current, detector readout noise and digitalization noise. Figure 1 depicts the OS limb radiance signal-to-noise ratio field for a typical Antarctic scan in the spectral range where $\mathrm{OClO}$ absorbs. If the reduced chi-squared values are much larger than one, the observed DOD does not fit the calculated DOD within the measurement errors. Tangent heights with $\chi_{\text {doas }}^{2}>4$ are excluded from the further analysis.

\subsection{Selection of the fitting interval}

Solomon et al. (1987) first retrieved OClO column abundances in the wavelength range of $403-428 \mathrm{~nm}$ using a spectrograph covering the region from 400 to $453 \mathrm{~nm}$. Spectroscopic measurements of $\mathrm{OClO}$ have also been performed in the near-UV region by other authors (e.g., Schiller et al., 1990; Perner et al., 1991; Perner et al., 1994; Brandtjen et al., 1994; Van Roozendael et al., 1995; Wagner et al., 2001), with the window $363-391 \mathrm{~nm}$ being the most frequently employed. 


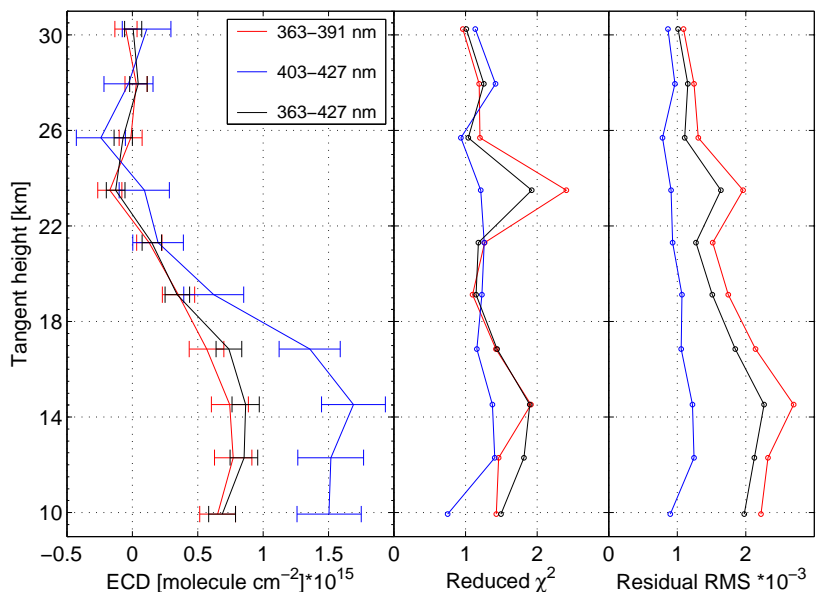

Fig. 2. Left panel: OClO ECD profiles retrieved from OSIRIS spectra measured on 19 September 2002 (scan 8567046, latitude $79.2^{\circ} \mathrm{S}$, longitude $18.2^{\circ} \mathrm{W}$, SZA $91.0^{\circ}, 17: 47 \mathrm{LST}$ ) in the 363 $391 \mathrm{~nm}, 403-427 \mathrm{~nm}$, and $363-427 \mathrm{~nm}$ fitting windows. The error bars represent the 1-STD uncertainties of the LSQ fit. Middle panel: reduced chi squared. Right panel: residual RMS.

The selection of the $\mathrm{OClO}$ fitting window is restricted to the $355-427 \mathrm{~nm}$ wavelength interval. Wavelengths shorter than $355 \mathrm{~nm}$ are problematic due to the temperature dependence of ozone cross sections in the Huggins bands and the non-linearity problems due to large optical depths. Because of a strong $N_{2}^{+}$auroral emission at $427.8 \mathrm{~nm}$ and the weak cross sections of $\mathrm{OClO}$ at longer wavelengths, wavelengths are limited to be shorter than $427 \mathrm{~nm}$. In this study, three spectral regions were investigated as possible fitting windows to retrieve OClO ECD: $363-391 \mathrm{~nm}, 403-427 \mathrm{~nm}$, and 363$427 \mathrm{~nm}$. Measurements in the 390.9-398.4 nm range are not included in the spectral fit due to the presence of a pair of deep Fraunhofer lines ( $\sim 393$ and $\sim 397 \mathrm{~nm})$ and a strong $N_{2}^{+}$ auroral emission at $391.4 \mathrm{~nm}$. For all windows a second order polynomial is used to obtain the differential quantities.

Other trace gases (i.e., $\mathrm{O}_{3}, \mathrm{NO}_{2}, \mathrm{O}_{4}$ and $\mathrm{BrO}$ ) absorb in the $\mathrm{UV}$-visible region, and thus their absorption cross sections are included along with $\mathrm{OClO}$ in the fit. Table 2 shows the specifications of the cross sections used in this study. It is important that the temperature dependence of the cross sections is considered in the DOAS fit. In particular, the Kromminga et al. (2003) OClO differential cross sections show a large temperature dependence, varying by up to $40 \%$ between 213 and $233 \mathrm{~K}$ in the $403-427 \mathrm{~nm}$ wavelength interval. However, the European Centre for Medium-range Weather Forecasts (ECMWF) analysis for the period in question for this study, the 19-20 September 2002 Antarctic vortex, suggests cold temperatures (i.e., $<200 \mathrm{~K}$ ) below that of the available cross sections. As a consequence, the absorption cross sections used in the DOAS fits were selected at the coldest temperatures available: $203 \mathrm{~K}$ for $\mathrm{O}_{3}$ (Bogumil et al., 2003), $\mathrm{NO}_{2}$ at $220 \mathrm{~K}$ (Vandaele et al., 1998), OClO at $213 \mathrm{~K}$ (Kromminga

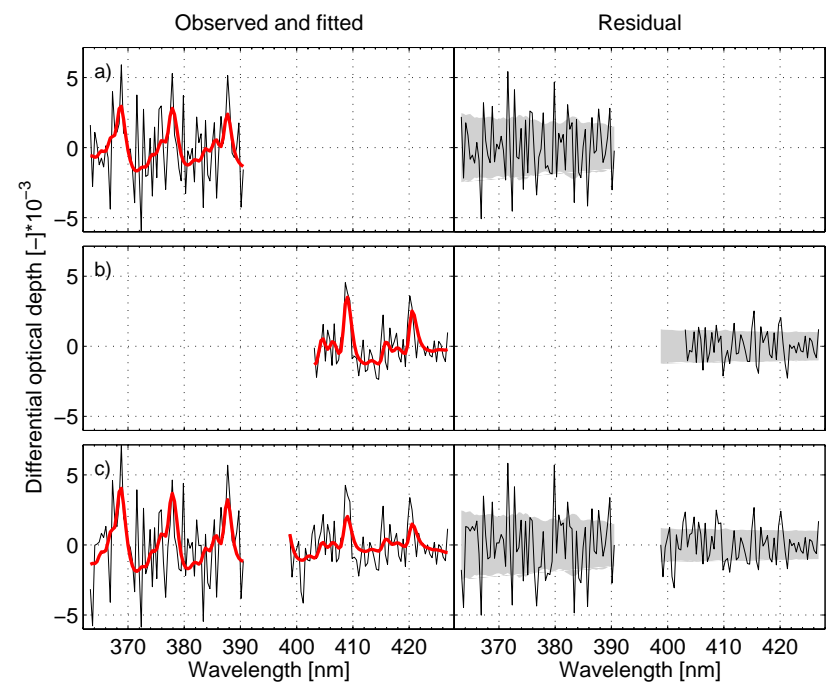

Fig. 3. OClO spectral fit of scan 8567046 at the tangent height of $16.8 \mathrm{~km}$ in the wavelength regions: (a) $363-391 \mathrm{~nm}$, (b) $403-$ $427 \mathrm{~nm}$, and (c) 363-427 nm. Left panels: Observed (black line) and fitted (red line) OClO DOD. Right panels: residual structures. The shaded regions represent the estimated 1-STD error in the observed DOD.

et al., 2003), and $\mathrm{O}_{4}$ at $296 \mathrm{~K}$ (Greenblatt et al., 1990). Table 3 displays the number of pixels $\eta$ of each window, excluded wavelength bands and interfering species in the different windows.

Figure 2 shows OClO ECD profiles, reduced chi squared and residual RMS values retrieved from OS spectra measured on 19 September 2002 in the three spectral regions. The wavelength interval 403-427 nm presents larger OClO ECD compared with the others at almost all the tangent heights. The mean residual RMS values are $1.8 \times 10^{-3}, 1.0 \times 10^{-3}$, and $1.6 \times 10^{-3}$ in the $363-391,403-427$, and $363-427 \mathrm{~nm}$ regions, respectively, with generally larger residual RMS values at lower tangent heights. $\chi_{\text {doas }}^{2}$ values are comparable in the three windows, with values at most tangent heights ranging between 1 and 2. The estimated accuracy of the $\mathrm{OClO}$ ECD at the peak is $12 \%, 14 \%$ and $19 \%$ in the $363-391,403-$ 427 , and $363-427 \mathrm{~nm}$ windows, respectively, based on the measurement errors.

Since a good reduced chi squared and small residual RMS may not mean necessarily that the fit and/or the fitting function are good, a visual examination of the residuals is performed to identify remaining patterns or systematic structures. Figure 3 presents the fitting residual values of the same scan shown in Fig. 2 at a tangent height of $16.8 \mathrm{~km}$ along with the observed and fitted OCIO DOD in the three windows. Although the residuals in the $403-427 \mathrm{~nm}$ region show some systematic structures, their values are small compared with the residuals of the other windows. These findings are confirmed with the results obtained when processing other OS spectra measured on 19-20 September 2002 inside the polar 
Table 2. Specifications of the absorption cross sections used in this study. The resolution is expressed as FWHM at $415 \mathrm{~nm}$, except for BrO cross sections whose FWHM is given at $370 \mathrm{~nm}$.

\begin{tabular}{lllll}
\hline Species & Source & Temperature $[\mathrm{K}]$ & FWHM & Interpolation in temperature \\
\hline $\mathrm{O}_{3}$ & Bogumil et al. (2003) & $203,223,243,273,293$ & $0.52 \mathrm{~nm}$ & Quadratic \\
$\mathrm{NO}_{2}$ & Vandaele et al. (1998) & 200,294 & $34 \mathrm{pm}$ & Linear \\
$\mathrm{OClO}$ & Kromminga et al. (2003) & $213,223,253,273,293$ & $17 \mathrm{pm}$ & Quadratic \\
$\mathrm{O}_{4}$ & Greenblat et al. (1990) & 296 & $0.56 \mathrm{~nm}$ & - \\
$\mathrm{BrO}$ & Wilmouth et al. (1999) & 228,298 & $0.14 \mathrm{~nm}$ & Linear \\
\hline
\end{tabular}

vortex area. The larger signal-to-noise ratio for $\lambda>\sim 400 \mathrm{~nm}$ (see Fig. 1) could, to some extent, explain the smaller residual structures found in the $403-427 \mathrm{~nm}$ window. A further detailed analysis should be conducted to investigate cause of the ECD and residual variations in the different windows.

Negative OClO ECD were frequently found at latitudes outside the polar vortex area at all tangent heights, and at tangent heights above $25 \mathrm{~km}$ within the vortex for spectra measured on 19-20 September 2002. As it is unlikely that OClO concentrations are large at high tangent heights, leading to significant absorption signatures in the reference spectrum, these negative values indicate that the $\mathrm{OClO}$ abundances are below the detection limit of the OS. Other authors (e.g., Solomon et al., 1987; Pommereau and Piquard, 1994) could not detect any significant $\mathrm{OClO}$ concentrations under similar conditions. The frequency of occurrence and the magnitude of these negative ECD values are smaller in the range 403$427 \mathrm{~nm}$ compared to the values calculated in the other windows. A possible explanation could be the smaller residual structures observed in this spectral window.

Based on these results, the window $403-427 \mathrm{~nm}$ has been chosen to retrieve $\mathrm{OClO}$ in this study.

\subsection{Spectral corrections}

Systematic structures in the residual spectra can be caused by the Ring effect, solar $I_{o}$ effect, polarization sensitivity of the instrument, effect of instrument resolution and sampling, and wavelength shifts. The reader is referred to Haley et al. (2004) for the details on the nature of these spectral corrections. In this section, the sensitivity of the derived $\mathrm{OClO}$ effective columns to these issues is analyzed by applying different spectral corrections to the OS spectra and absorption cross sections. The spectra were chosen from 122 scans, measured on 19-20 September 2002 inside the chlorine activation area, at tangent heights between 10 and $30 \mathrm{~km}$. This study was carried out in a sequence of several steps as follows:

1. The variables OClO ECD, OClO ECD relative error, $\chi_{\text {doas }}^{2}$, and residual RMS are derived when no correction is used in the retrieval process (run 1). The OClO
Table 3. Investigated spectral fitting windows for the $\mathrm{OClO}$ retrievals.

\begin{tabular}{llll}
\hline Window $[\mathrm{nm}]$ & $\eta$ & Excluded $\lambda[\mathrm{nm}]$ & Interfering species \\
\hline $363-391$ & 71 & - & $\mathrm{O}_{3}, \mathrm{NO}_{2}, \mathrm{O}_{4}, \mathrm{BrO}$ \\
$403-427$ & 61 & - & $\mathrm{O}_{3}, \mathrm{NO}_{2}, \mathrm{O}_{4}$ \\
$363-427$ & 142 & $390.9-398.4$ & $\mathrm{O}_{3}, \mathrm{NO}_{2}, \mathrm{O}_{4}, \mathrm{BrO}$ \\
\hline
\end{tabular}

ECD relative error is calculated by dividing the $\mathrm{OClO}$ ECD error by its corresponding OClO ECD.

2. The same variables are calculated when the first spectral correction is taken into account (run 2).

3. For each variable, the results of run 1 are subtracted from the results of run 2 .

4. These differences are then classified as positive or negative increments. Differences larger than $100 \%$ or smaller than $-100 \%$ represent only a few percent of the total number of measurements and were discarded from this analysis.

5. The relative frequencies (i.e., the number of measurements following this condition divided by the total number of measurements) of the positive and negative differences are calculated for each variable.

6. The mean values of the positive and negative increments are computed separately for each variable.

7. After analyzing the results obtained in steps 5 and 6 , it is decided if the spectral correction is included or not in the subsequent runs.

The above procedure is employed to investigate the sensitivity of the OCIO ECD profiles to various spectral corrections: Rayleigh scattering, solar $I_{o}$ effect, Ring effect, polarization, tilt effect, and wavelength shifts. Tables 4, 5, 6, and 7 display separately the positive and negative mean differences of the OClO ECD, OClO ECD relative error, residual RMS and $\chi_{\text {doas }}^{2}$, respectively, together with the relative frequencies 
Table 4. Positive and negative mean differences of OClO ECD and their relative frequencies when including each of these spectral corrections: Rayleigh, $I_{O}$, Ring, tilt, polarization and wavelength shift.

\begin{tabular}{lcccc}
\hline & \multicolumn{2}{c}{ Positive differences } & \multicolumn{2}{c}{ Negative differences } \\
\hline Correction & Mean [\%] & Frequency [\%] & Mean [\%] & Frequency [\%] \\
\hline Rayleigh & 27 & 50 & -31 & 31 \\
$I_{O}$ & 8 & 64 & -13 & 32 \\
Ring & 32 & 59 & -45 & 18 \\
Tilt & 11 & 71 & -10 & 26 \\
Polarization & 3 & 61 & -4 & 38 \\
$\lambda-$ shift & 11 & 43 & -11 & 45 \\
\hline
\end{tabular}

Table 5. Positive and negative mean differences of OClO ECD relative error and their relative frequencies when including each of these spectral corrections: Rayleigh, $I_{O}$, Ring, tilt, polarization and wavelength shift.

\begin{tabular}{lcccc}
\hline & \multicolumn{2}{c}{ Positive differences } & \multicolumn{2}{c}{ Negative differences } \\
\hline Correction & Mean [\%] & Frequency [\%] & Mean [\%] & Frequency [\%] \\
\hline Rayleigh & 25 & 35 & -26 & 47 \\
$I_{O}$ & 14 & 28 & -8 & 69 \\
Ring & 47 & 10 & -29 & 73 \\
Tilt & 8 & 25 & -10 & 73 \\
Polarization & 4 & 39 & -3 & 60 \\
$\lambda-$ shift & 10 & 48 & -11 & 45 \\
\hline
\end{tabular}

Table 6. Positive and negative mean differences of residual RMS and their relative frequencies when including each of these spectral corrections: Rayleigh, $I_{O}$, Ring, tilt, polarization and wavelength shift.

\begin{tabular}{lcccc}
\hline & \multicolumn{2}{c}{ Positive differences } & \multicolumn{2}{c}{ Negative differences } \\
\hline Correction & Mean [\%] & Frequency [\%] & Mean [\%] & Frequency [\%] \\
\hline Rayleigh & 0.1 & 3 & -1 & 97 \\
$I_{O}$ & 1 & 43 & -1 & 57 \\
Ring & 4 & 97 & -1 & 1 \\
Tilt & 0 & 0 & -12 & 100 \\
Polarization & 0.1 & 3 & -1 & 97 \\
$\lambda-$ shift & 4 & 51 & -2 & 47 \\
\hline
\end{tabular}

Table 7. Positive and negative mean differences of $\chi_{\text {doas }}^{2}$ and their relative frequencies when including each of these spectral corrections: Rayleigh, $I_{O}$, Ring, tilt, polarization and wavelength shift.

\begin{tabular}{lcccc}
\hline & \multicolumn{2}{c}{ Positive differences } & \multicolumn{2}{c}{ Negative differences } \\
\hline Correction & Mean [\%] & Frequency [\%] & Mean [\%] & Frequency [\%] \\
\hline Rayleigh & 1 & 66 & -3 & 34 \\
$I_{O}$ & 2 & 44 & -1 & 56 \\
Ring & 9 & 97 & -2 & 1 \\
Tilt & 1 & 13 & -24 & 87 \\
Polarization & 1 & 70 & -3 & 30 \\
$\lambda$-shift & 8 & 51 & -4 & 47 \\
\hline
\end{tabular}


of these increments for each spectral correction. As an example, when the tilt correction is taken into account $71 \%$ of the OClO ECD increments are positive with a mean increase of $11 \%$ while $26 \%$ of the increments are negative with a mean difference value of $-10 \%$ (see Table 4 ).

\subsubsection{Rayleigh scattering}

The spectral smoothing applied to obtain the differential quantities is performed by a second order closure polynomial in the $403-427 \mathrm{~nm}$ region. Rayleigh cross sections (from Bates, 1984) are included in the least squares (LSQ) fit to complete the removal of this 4 th order polynomial structure. This correction is especially important for the lower stratosphere where Rayleigh scattering is more efficient. The Rayleigh correction yields a mean increase of $27 \%$ in the OClO ECD for $50 \%$ of the cases, while it reduces the residual RMS by $1 \%$ for almost all the cases. In light of this, this correction is included in the retrieval process.

\subsubsection{Solar $I_{o}$ effect}

The absorption cross sections of the trace gases used in this DOAS analysis are taken from the literature. OS spectra and laboratory absorption cross sections are measured at different spectral resolutions and using different light sources. Thus, highly resolved and temperature-dependent absorption cross sections are convolved to the OS resolution and $I_{O}$-corrected following Haley et al. (2004). The difference between the uncorrected and $I_{o}$-corrected cross sections is larger for $\mathrm{OClO}$ (up to 4\%) than for the interfering species in the 403-427 nm fitting region. Accounting for the $I_{o}$ effect increases the OClO effective columns by an average of $8 \%$ in $64 \%$ of the cases and their relative errors decrease $8 \%$ in $69 \%$ of the cases. As a result, the $I_{o}$-corrected cross sections are used in this work.

\subsubsection{Ring effect}

The Ring effect refers to the broadening and reduction of depth of the spectral features compared to the unattenuated spectrum, and is mainly caused by rotational Raman scattering. An iterative backward Ring model (Sioris et al., 2002) is used to remove the Ring effect from OS limb spectra, before performing the DOAS LSQ fit. When the Ring effect is considered, the residual RMS are even larger and $\chi_{\text {doas }}^{2}$ values increase away from one for almost all the cases, indicating a poorer fit. This is consistent with the results found by Haley et al. (2004) and Sioris et al. (2003) when retrieving $\mathrm{NO}_{2}$. An explanation for this could be that the lack of strong Fraunhofer lines in the 403-427 nm window combined with the use of a high tangent height reference from within the scan leads to a minimization of the effect. The fact that the Ring effect correction mostly impairs the spectral fit can also be an indication of an inappropriate modelling of the Ring effect. As a result, the Ring effect is not considered when retrieving OCIO ECD in the $403-427 \mathrm{~nm}$ window.

\subsubsection{Tilt effect}

The Fraunhofer lines observed in the reference tangent height spectrum and a lower tangent height spectrum can appear shifted and skewed relative to each other. This effect, denoted "tilt effect", is mainly explained by the undersampling of the OS spectra ( $\sim 2$ pixels/FWHM) in combination with Rayleigh and Mie trending (tilt) of the limb radiances. The tilt effect can be roughly accounted for by introducing a pseudoabsorber in the DOAS LSQ fit. Sioris et al. (2003) calculated the tilt pseudoabsorber $t$ by subtracting a quadratic function from the ratio of two modelled spectral limb radiances (convolved to the OS resolution and sampling) at a high and at a low tangent height for a non-absorbing atmosphere. Haley et al. (2004) proposed two modifications to the approach of Sioris et al. (2003). The first modification is to remove the trending in the ratio of the convolved and sampled radiances, $I^{o s}$, with the ratio of the modelled highresolution radiances at a high and at a low tangent height, $I^{h r}$, rather than using a quadratic polynomial. The second change is to employ the logarithmic ratios of the radiances to be consistent to what is fitted in the DOAS LSQ fit. In this way, the tilt pseudoabsorber at wavelength $\lambda$ and at tangent height $h_{t}$ can be expressed as

$t\left(\lambda, h_{t}\right)=\ln \left[\frac{I^{O S}\left(\lambda, h_{t}^{r e f}\right)}{I^{O S}\left(\lambda, h_{t}\right)}\right]-\ln \left[\frac{I^{h r}\left(\lambda, h_{t}^{r e f}\right)}{I^{h r}\left(\lambda, h_{t}\right)}\right]$,

where $h_{t}^{\text {ref }}$ is the reference (high) tangent height. If the tilt contribution is small $(t<<1)$, Eq. (4) can be approximated as

$1+t\left(\lambda, h_{t}\right) \approx \frac{I^{O S}\left(\lambda, h_{t}^{r e f}\right) I^{h r}\left(\lambda, h_{t}\right)}{I^{O S}\left(\lambda, h_{t}\right) I^{h r}\left(\lambda, h_{t}^{r e f}\right)}$.

In Haley et al. (2004), limb radiances modeled at $10 \mathrm{~km}$ and $50 \mathrm{~km}$ were used to create a fixed tilt pseudoabsorber. In this study, the LIMBTRAN radiative transfer model is used to simulate spectral limb radiances at different tangent heights under Antarctic spring conditions (large SZA and high ground albedo). A set of tilt pseudoabsorbers is calculated with Eq. (5) at tangent heights between $10 \mathrm{~km}$ and $40 \mathrm{~km}$ with a $2 \mathrm{~km}$ interval with a $50 \mathrm{~km}$ reference tangent height. The fixed $50 \mathrm{~km}$ reference tangent height simplifies calculations and well represents the reference used for the measurements (mean reference tangent height of the 122 scans equal to $48.2 \mathrm{~km}$ ). The tilt pseudoabsorber for a specific tangent height is then linearly interpolated from this set of pre-calculated tilt pseudoabsorbers. Figure 4 displays the tilt pseudoabsorber at four tangent heights $(10,20,30$ and $40 \mathrm{~km}$ ) in the $403-427 \mathrm{~nm}$ window. It was found that the usage of this tangent height dependent tilt spectrum calculated for Antarctic spring conditions produces better results compared to the results obtained when fitting a fixed tilt 


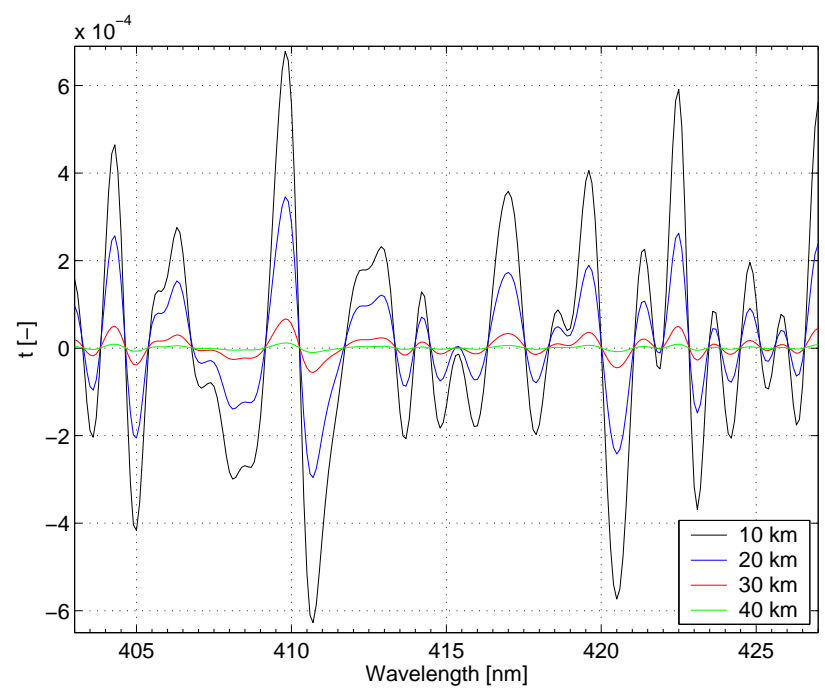

Fig. 4. Simulated tilt pseudoabsorber at 10, 20, 30, and $40 \mathrm{~km}$ tangent height in the spectral interval $403-427 \mathrm{~nm}$.

pseudoabsorber by accounting for the changes in the spectral structure of the tilt effect with tangent height. A large improvement in the DOAS fit is observed for almost all the scans when the tilt effect is considered. The residual RMS decreases $12 \%$ for all the cases whereas $\chi_{\text {doas }}^{2}$ diminishes $24 \%$ in $87 \%$ of the cases. The improvement of the fit also leads to larger $\mathrm{OClO}$ abundances in $71 \%$ of the cases with an average increase of $11 \%$. As a consequence, the tilt pseudoabsorber is included in the LSQ fit.

\subsubsection{Polarization}

The polarization parameter accounts for structures in the spectra due to the interaction of the polarized radiances with the grating. The OS polarization efficiency parameter was computed in the $403-427 \mathrm{~nm}$ window as described by McLinden et al. (2002). Because this parameter is not completely removed by a second order polynomial, it is included as a pseudoabsorber in the LSQ fit at all tangent heights in the sensitivity analysis. However, as the analysis shows, the polarization correction has a small impact on the $\mathrm{OClO}$ columns and their relative errors as well as on the other statistics, and is not included in the OClO ECD fits.

\subsubsection{Wavelength shift}

The wavelength calibration of the OS has been determined by applying two methods. A Levenberg-Marquardt (LM) (Levenberg, 1944; Marquardt, 1963) fit of a high resolution solar spectrum (Kurucz, http://kurucz.harvard.edu/ sun/IRRADIANCE/irradiancebins.dat) to OS limb radiance spectra at mesospheric altitudes has been performed to the blue part of the spectrum. To the red end of the spectrum, the wavelength calibration was determined by using intense air-

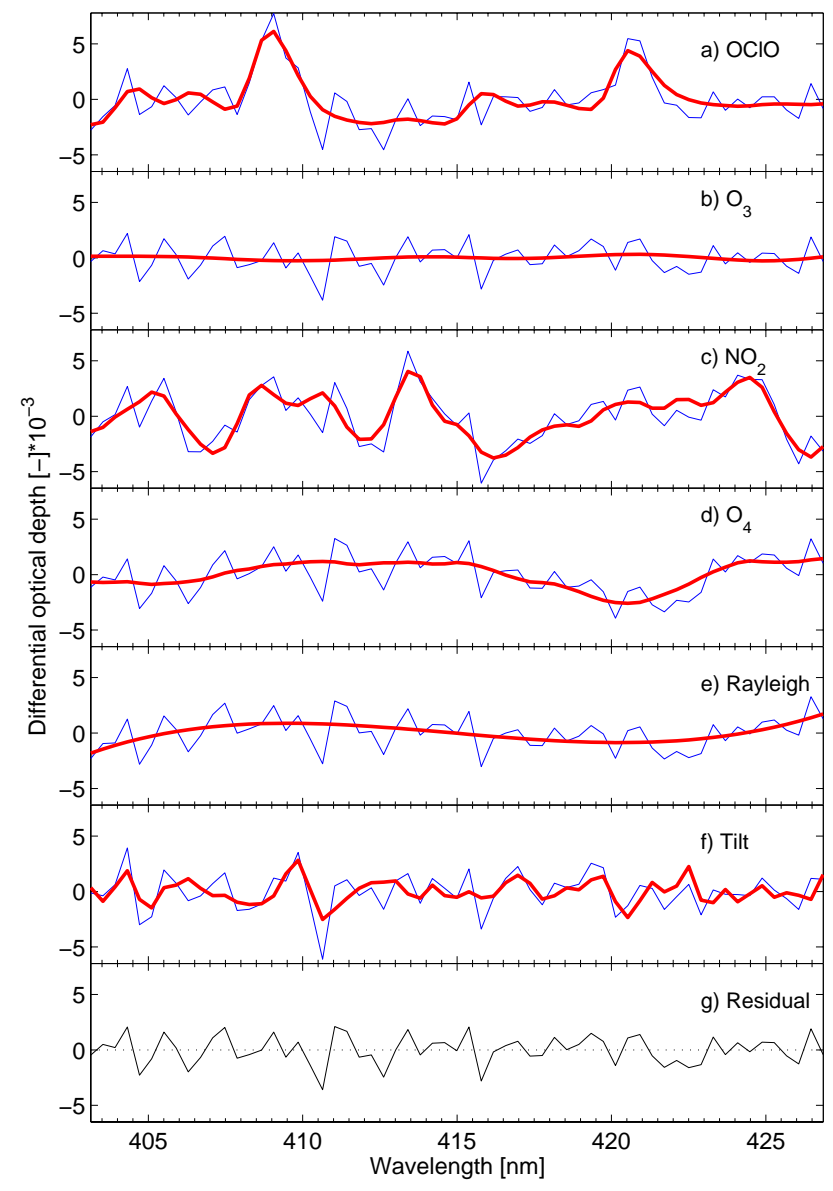

Fig. 5. Typical example of the observed (blue line) and fitted (red line) DOD of: (a) $\mathrm{OClO}$, (b) $\mathrm{O}_{3}$, (c) $\mathrm{NO}_{2}$, (d) $\mathrm{O}_{4}$, (e) Rayleigh, (f) tilt in the $403-427 \mathrm{~nm}$ region. The residual structures are also shown in panel (g). The corresponding OS measurement was performed at $18.7 \mathrm{~km}$ tangent height on 19 September 2002 (scan 8565047 , latitude $81.7^{\circ} \mathrm{S}$, longitude $36.4^{\circ} \mathrm{E}$, SZA $\left.92.0^{\circ}, 18: 10 \mathrm{LST}\right)$.

glow features, Fraunhofer lines, and $\mathrm{O}_{2}$ absorption features (C. E. Sioris and C. S. Haley, private communication). However, this is only a nominal calibration and any wavelength misalignment between the measured limb-scattered radiance spectra and the absorption cross sections could affect the DOAS fit. It is not expected that OS pixel wavelengths vary over the duration of a scan because of the short time period $(\sim 90 \mathrm{~s})$ and the temperature stability of OS. Thus, an absolute shift in wavelength is determined through L-M non-linear iterations on the DOAS fit to the lowest tangent height measurement and then applied to all measurements in the scan. After processing the set of 122 scans, a $0.03 \mathrm{~nm}$ average shift was found, but with large standard deviations $(0.045 \mathrm{~nm})$, indicating that the derived shift was dominated by the noise in the measurement. In light of this, the wavelength shift is not applied when retrieving the OClO ECD. 
As a result of these sensitivity tests, Rayleigh scattering, $I_{o}$ effect, and tilt effect are the spectral corrections applied when retrieving $\mathrm{OClO}$ in the $403-427 \mathrm{~nm}$ region. Figure 5 presents a typical fit showing the fitted and observed DOD of $\mathrm{OClO}, \mathrm{O}_{3}, \mathrm{NO}_{2}$, and $\mathrm{O}_{4}$, Rayleigh and tilt together with the residual structures at $18.7 \mathrm{~km}$ tangent height inside the polar vortex area.

\subsection{Inversion}

The objective of the inversion is to convert the OClO ECD as a function of tangent height, obtained from the DOAS analysis, to number density as a function of altitude. The problem is best approached with the use of a forward model $\boldsymbol{F}$ that relates the vector of OCIO ECD for a set of tangent heights $c$ to the number density vector $\boldsymbol{n}$ by

$\boldsymbol{c}\left(h_{t}\right)=\boldsymbol{F}\left(\boldsymbol{n}, \boldsymbol{b}, h_{t}\right)+\varepsilon$,

where $\boldsymbol{b}$ is the vector of model parameters that are not retrieved and $\varepsilon$ is the measurement error.

The inversion algorithm employed in this work is the maximum a posterior estimation method (Rodgers, 2000). MAP combines measurements with a priori information about the profile to find the best estimate of the true profile and its error covariance. This is done by maximizing the a posteriori probability density function of the state $\boldsymbol{n}$ given the measurement $\boldsymbol{c}$. If Gaussian statistics are assumed for variables and errors, the MAP estimator leads to the minimization of the following cost function $J$ (Rodgers, 2000):

$$
\begin{aligned}
J(\boldsymbol{n}) & =[\boldsymbol{c}-\boldsymbol{F}(\boldsymbol{n}, \boldsymbol{b})]^{T} \mathbf{S}_{\varepsilon}^{-1}[\boldsymbol{c}-\boldsymbol{F}(\boldsymbol{n}, \boldsymbol{b})] \\
& +\left[\boldsymbol{n}-\boldsymbol{n}_{a}\right]^{T} \mathbf{S}_{a}^{-1}\left[\boldsymbol{n}-\boldsymbol{n}_{a}\right],
\end{aligned}
$$

where $\boldsymbol{n}_{a}$ is the a priori number density state vector, $\mathbf{S}_{a}$ is the a priori covariance matrix, and $\mathbf{S}_{\varepsilon}$ is the measurement error covariance matrix. $\mathbf{S}_{\varepsilon}$ is a diagonal matrix since $\varepsilon$ is assumed to be uncorrelated in tangent height. In order to avoid negative values that could lead to unstable retrievals, the natural logarithm of the concentration $\ln (\boldsymbol{n})$ is inverted instead of the concentration $\boldsymbol{n}$. Note that this positive constraint necessitates a non-linear retrieval. For clarity, the following discussion assumes that just the concentrations are being inverted.

If the inversion problem was linear the forward model could be expressed as $\boldsymbol{F}=\mathbf{K} \boldsymbol{n}$, where $\mathbf{K}$ is the weighting function matrix, and the minimization of $J$ could be analytically solved. However, for a non-linear problem it must be solved numerically and iteratively. To this end, a simplified Levenberg-Marquardt iterative scheme has been chosen to minimize $J$, yielding the following solution:

$$
\begin{aligned}
& \boldsymbol{n}_{i+1}=\boldsymbol{n}_{i}+\left[\left(1+\gamma_{i}\right) \mathbf{S}_{a}^{-1}+\mathbf{K}_{i}^{T} \mathbf{S}_{\varepsilon}^{-1} \mathbf{K}_{i}\right]^{-1} \\
& {\left[\mathbf{K}_{i}^{T} \mathbf{S}_{\varepsilon}^{-1}\left(\boldsymbol{c}-\boldsymbol{F}\left(\boldsymbol{n}_{i}, \boldsymbol{b}\right)\right)-\mathbf{S}_{a}^{-1}\left(\boldsymbol{n}_{i}-\boldsymbol{n}_{a}\right)\right],}
\end{aligned}
$$

where the weighting function matrix $\mathbf{K}_{i}$ is calculated for each iteration step $i$ (see Sect. 3.4.3) and $\gamma_{i}$ determines the step size of the iteration. The simplified L-M method is a combination of the steepest descent and Gauss-Newton (G-N) methods where $\gamma_{i}$ is the parameter controlling the balance between them (Rodgers, 2000).

Two different strategies were applied in this investigation. The first one is to find the solution within 10 iterations using the G-N method $\left(\gamma_{i}=0\right)$ since the G-N method converges faster. When an occasional fail in convergence occurs, the L-M scheme is applied. Large $\gamma_{i}$ values are set during the first iterations of L-M to descend with small steps. Once the solution is closer to the minimum, small $\gamma_{i}$ values are chosen. In both cases, the iteration is halted when the size of the step $\left(\boldsymbol{n}_{i+1}-\boldsymbol{n}_{i}\right)$ is smaller than the estimated error. The convergence criterion is expressed as

$$
\frac{\left(\boldsymbol{n}_{i+1}-\boldsymbol{n}_{i}\right)^{T} \hat{\mathbf{S}}^{-1}\left(\boldsymbol{n}_{i+1}-\boldsymbol{n}_{i}\right)}{p}<\Delta n,
$$

where $p$ is the number of heights in $\boldsymbol{n}, \Delta n$ is the absolute convergence tolerance, $\hat{\mathbf{S}}$ is the covariance matrix of the solution, and $\hat{\mathbf{S}}^{-1}\left(\boldsymbol{n}_{i+1}-\boldsymbol{n}_{i}\right)$ can be approximated by

$$
\hat{\mathbf{S}}^{-1}\left(\boldsymbol{n}_{i+1}-\boldsymbol{n}_{i}\right) \approx \mathbf{K}_{i}^{T} \mathbf{S}_{\varepsilon}^{-1}\left[\boldsymbol{c}-\boldsymbol{F}\left(\boldsymbol{n}_{i}, \boldsymbol{b}\right)\right]-\mathbf{S}_{a}^{-1}\left[\boldsymbol{n}_{i}-\boldsymbol{n}_{a}\right] .
$$

In this study, $\Delta n$ is set to 0.01 . When Eq. (8) has converged to some value $\hat{\boldsymbol{n}}$ with corresponding $\hat{\mathbf{K}}$, a standard $\chi^{2}$ test is carried out to determine whether the difference between the retrieved and measured quantities is statistically significant at some appropriate level. Following Rodgers (2000), the reduced chi-squared statistic for the inversion is defined by

$\chi_{\mathrm{inv}}^{2}=\frac{[\boldsymbol{c}-\boldsymbol{F}(\hat{\boldsymbol{n}}, \boldsymbol{b})]^{T} \mathbf{S}_{\delta \hat{c}}^{-1}[\boldsymbol{c}-\boldsymbol{F}(\hat{\boldsymbol{n}}, \boldsymbol{b})]}{q}$,

where $\mathbf{S}_{\delta \hat{c}}=\mathbf{S}_{\varepsilon}\left[\hat{\mathbf{K}} \mathbf{S}_{a} \hat{\mathbf{K}}^{T}+\mathbf{S}_{\varepsilon}\right]^{-1} \mathbf{S}_{\varepsilon}$, is the covariance matrix of $\delta \hat{\boldsymbol{c}}=\boldsymbol{c}-\boldsymbol{F}(\hat{\boldsymbol{n}}, \boldsymbol{b})$, and $q$ is the number of tangent heights in c. Profiles with $\chi_{\text {inv }}^{2}>4$ are discarded.

\subsubsection{The forward model}

A radiative transfer model (RTM) is used to simulate the limb-scattered radiances at different tangent heights for a specified wavelength range and a given atmospheric state. Simulated optical depths are then calculated and subjected to a DOAS analysis. The resulting effective column densities constitute the forward model $\boldsymbol{F}$. In a trade-off between computational efficiency and accuracy, the pseudo-spherical multiple scattering radiative transfer model LIMBTRAN (Griffioen and Oikarinen, 2000) is applied in the inversion procedure. Temperature and pressure are taken from the ECMWF analysis fields. The $\mathrm{O}_{3}$ mean state distribution is taken from the four-dimensional climatology of $\mathrm{Li}$ and Shine (1995) which is based on satellite and ozonesonde data sets. The $\mathrm{NO}_{2}$ information is taken from a climatology constructed using the PRATMO photochemical box model (Prather and 


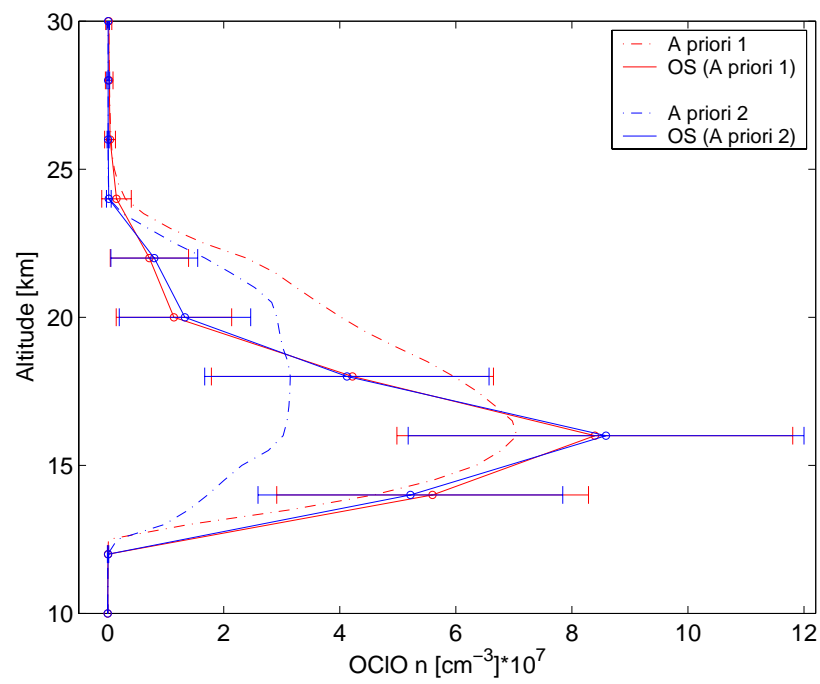

Fig. 6. Sensitivity of the OS OClO profile (scan 8565047 , latitude $81.7^{\circ} \mathrm{S}$, longitude $36.4^{\circ} \mathrm{E}$, SZA $92.0^{\circ}, 18: 10 \mathrm{LST}$ ) to the a priori OClO profile. Two REPROBUS OClO profiles have been chosen as a prioris: 1) corresponds to the coincident OS profile, and 2) corresponds to scan 8565045 (latitude $87.6^{\circ} \mathrm{S}$, longitude $165.0^{\circ} \mathrm{W}$, SZA $\left.92.1^{\circ}, 4: 43 \mathrm{LST}\right)$. The error bars of the estimated OS retrieval errors $\left(S_{m}+S_{S}\right)$ are also shown.

Jaffe, 1990; McLinden et al., 2000) that accounts for the diurnal variation of this species. The $\mathrm{OClO}$ a priori distribution is described in Sect. 3.4.2. The temperature-dependent cross sections employed in LIMBTRAN are the same as those used for the DOAS spectral fitting and are listed in Table 2. The $\mathrm{O}_{3}$ and $\mathrm{OClO}$ cross sections are interpolated in temperature within the model by using a quadratic polynomial as recommended by Orphal (2003) and Kromminga et al. (2003), respectively. A linear function is used to reproduce the temperature dependence of the $\mathrm{NO}_{2}$ cross sections as suggested by Orphal (2003). A simple stratospheric aerosol model is included based on fitted parameters as a function of season and tropopause height (McCormick et al., 1996). The ground albedo is derived from the climatology of GOME Lambertian-Equivalent Reflectivity of the Earth's surface (Koelemeijer et al., 2003). The reader is referred to Haley et al. (2004) for more details on the simulation of OS radiances with this model.

\subsubsection{A priori information}

The most satisfactory source of a priori information is from independent high spatial resolution measurements (Rodgers, 2000). However, a climatology of such measurements is not available for $\mathrm{OClO}$. Thus, the a priori information is simulated with the REPROBUS chemical transport model (Lefèvre et al., 1994, 1998). This three-dimensional model takes into account the heterogeneous chemical reactions produced on the surface of the PSCs and extends from the ground up to $0.1 \mathrm{hPa}$ on 42 levels. In this work, the model was integrated from 1 July 2002 until 1 December 2002 in a $2^{\circ}$ latitude by $2^{\circ}$ longitude horizontal grid and a $15 \mathrm{~min}$ time step. The kinetic and photochemical data are based on Sander et al. (2000) for this particular study. Temperatures, winds and surface pressure analyzed every 6 hours by the ECMWF were employed in the simulations. The ozone field was initialized on 1 July 2002 from the three-dimensional ECMWF ozone analysis whereas other species were initialized from a June zonal mean computed from a REPROBUS long-term simulation. The generated vertical profiles are taken from the model grid points closest to the location and time of the selected OS measurements.

The OClO state is assumed to be log-normal and the species variability is modelled by

$S_{a}(i, j)=\rho^{2} \exp \left[\frac{-|z(i)-z(j)|}{l_{c}}\right]$,

where $z$ is the altitude indexed by $i$ and $j, \rho$ is the standard deviation of the diagonal components, and $l_{c}$ is the correlation length of the off-diagonal elements. Note that $\rho$ is the standard deviation of the a priori in linear space, before the translation to the logarithmic space. A reliable climatology of the vertical OClO variability is essential to determine $\rho$ and $l_{c}$. Since such a statistics does not exist, a sensitivity study was carried out by using different values of $\rho$ $(100 \%, 200 \%, 300 \%$, and $400 \%)$ and $l_{c}(3 \mathrm{~km}$ and $4 \mathrm{~km})$. In a trade-off between vertical resolution and retrieval error, $\rho$ was set to $300 \%$ and $l_{c}$ to $4 \mathrm{~km}$. Figure 6 shows the sensitivity of the retrieved $\mathrm{OS} \mathrm{OClO}$ profile to the a priori $\mathrm{OClO}$ profile. Two REPROBUS OClO profiles have been chosen as a prioris: one corresponding to the coincident OS profiles, and a second corresponding to a different location and time. Within the altitude region of good measurement sensitivity (see Sect. 3.4.4.), the OS retrievals are apparently quite insensitive to the a priori since the difference between the retrieved profiles lies within the error bars.

\subsubsection{Weighting functions}

$\mathbf{K}$ is the $q \times p$ weighting function matrix that represents the forward model response to changes in the atmospheric state. The rows of $\mathbf{K}$ are called weighting functions and the computation of the elements of $\mathbf{K}$ requires the derivation of the forward model. For clarity, only the linear version of $\mathbf{K}$ is shown and an element of the $\mathbf{K}$ matrix is expressed as

$K(i, j)=\frac{\partial F\left[\boldsymbol{n}, \boldsymbol{b}, h_{t}(i)\right]}{\partial n[z(j)]}$,

where the forward model is evaluated at tangent height $h_{t}(i)$ and $n[z(j)]$ is the number density at altitude $z(j)$. The weighting functions are determined numerically by using finite differences with sequential perturbation (5\% in this case) 


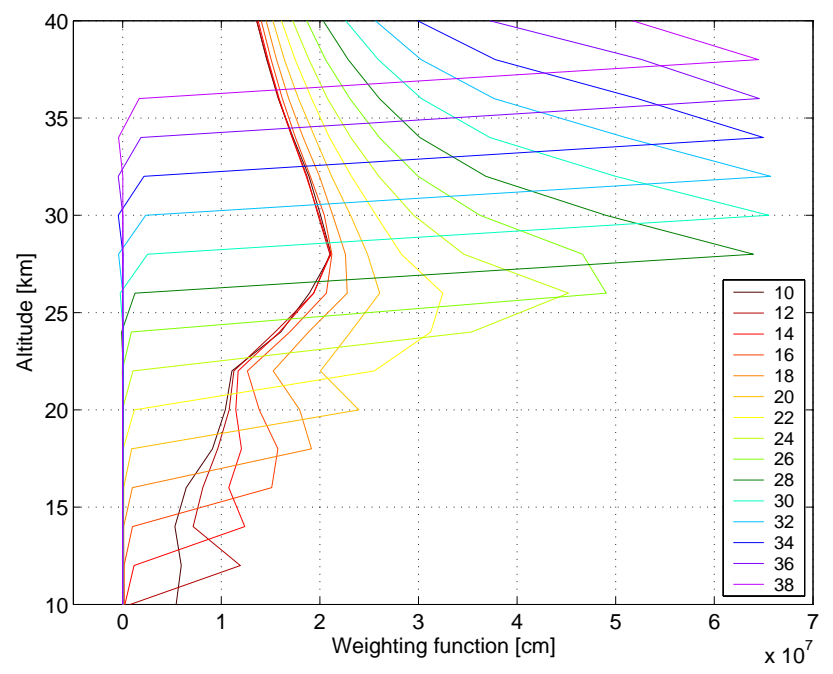

Fig. 7. OClO linear weighting functions calculated by using radiances at 409 and $412 \mathrm{~nm}, 5 \%$ perturbation, SZA $91^{\circ}$, ground albedo 0.8 , multiple scattering and no aerosols. The legend displays the tangent heights expressed in $\mathrm{km}$.

of the elements of $\boldsymbol{n}$. An element of the $\mathbf{K}$ matrix is thus approximated as

$K(i, j) \approx \frac{F\left[\tilde{\boldsymbol{n}}, \boldsymbol{b}, h_{t}(i)\right]-F\left[\boldsymbol{n}, \boldsymbol{b}, h_{t}(i)\right]}{\tilde{n}[z(j)]-n[z(j)]}$,

where $\tilde{\boldsymbol{n}}$ is the number density vector perturbed in the region of $z(j)$.

This perturbation method is computationally expensive since the forward model has to be run $p$ times to estimate $\mathbf{K}$ for every iteration. As a result, two simplifications have been implemented when calculating $\mathbf{K}$. The first approximation is to reduce the number of spectral elements by using a two-wavelength DOAS approach as proposed by Haley et al. (2004). In this work, the wavelengths $412 \mathrm{~nm}$ and $409 \mathrm{~nm}$ were chosen as the strong and weak $\mathrm{OClO}$ absorption wavelengths, respectively. Other species do not significantly interfere with $\mathrm{OClO}$ at these wavelengths. This simplification does not lead to any significant differences when compared to a full DOAS analysis. The second simplification is to assume an aerosol-free atmosphere when simulating limb-scattered radiance spectra with the LIMBTRAN model. This approximation leads to negligible errors in the $\mathrm{OClO}$ retrievals. A selection of wavelengths is also applied to compute $\boldsymbol{F}$, and a $2 \mathrm{~nm}$ wavelength grid is found to be suitable in the 403$427 \mathrm{~nm}$ spectral range.

Figure 7 depicts the $\mathrm{OClO}$ linear weighting functions computed for spring Antarctic conditions. Each plotted profile exhibits how much the OClO ECD [molecule $\mathrm{cm}^{-2}$ ] at a given tangent height would change if the number densities [molecule $\mathrm{cm}^{-3}$ ] at the various profile levels were changed. For instance, if the $\mathrm{OClO}$ number density at $26 \mathrm{~km}$ were to increase by 1 molecule $\mathrm{cm}^{-3}$, the OClO ECD at $26 \mathrm{~km}$ tan-

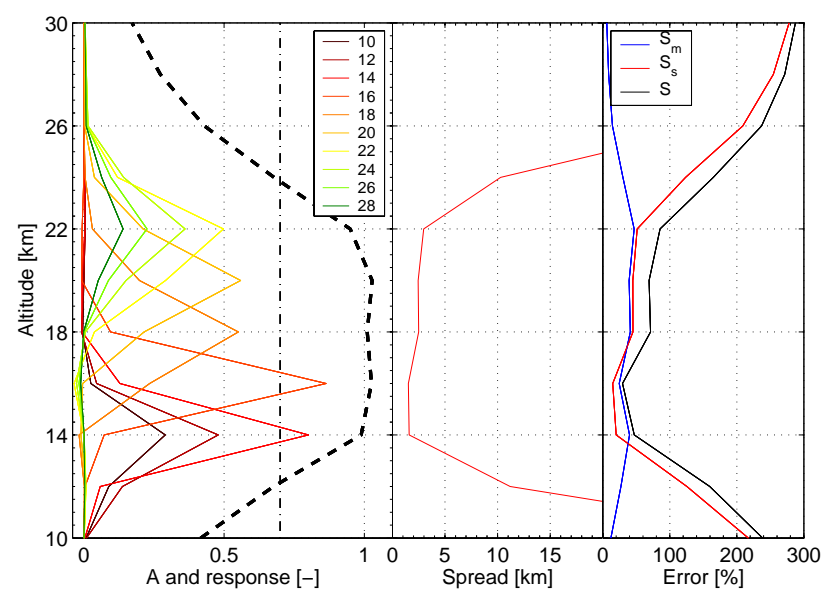

Fig. 8. Left panel: $\mathrm{OClO}$ averaging kernel functions with corresponding altitudes given in $\mathrm{km}$, measurement response $w$ (dashed line), and $w=0.7$ (dashed-dotted line) for the OSIRIS scan 8567045 (latitude $83.9^{\circ} \mathrm{S}$, longitude $18.5^{\circ} \mathrm{W}, \mathrm{SZA} 91^{\circ}$ ). $l_{c}$ was set to $4 \mathrm{~km}$ and $\rho$ to $300 \%$. Middle panel: spread $s$. Right panel: OClO number density errors: retrieval noise $S_{m}$, smoothing error $S_{s}$, and retrieval error $S=S_{m}+S_{s}$.

gent height would increase by $4.9 \times 10^{7}$ molecule $\mathrm{cm}^{-2}$. The OClO ECD at tangent heights above $24 \mathrm{~km}$ are mostly influenced by $\mathrm{OClO}$ concentrations near and slightly above the tangent point. The weighting functions show a pronounced step directly below the tangent height because the layers below have a small contribution in the limb viewing geometry. At lower tangent heights, the weighting functions become broader and peak around $26 \mathrm{~km}$ altitude, indicating larger contributions from higher altitudes than from the tangent point region. The rapid decrease observed in the weighting functions at low tangent heights is due to the increasing Rayleigh scattering optical depths.

\subsubsection{Inversion characterization}

The vertical resolution of the retrieval is characterized by the width of the averaging kernel functions, defined as the rows of the averaging kernel matrix A. In this work, the spread $s$ (Backus and Gilbert, 1970) is used as a measure of this width

$s(z)=12 \frac{\int\left(z-z^{\prime}\right)^{2} \mathbf{A}^{2}\left(z, z^{\prime}\right) d z^{\prime}}{\left[\int\left|\mathbf{A}\left(z, z^{\prime}\right)\right| d z^{\prime}\right]^{2}}$,

where $z$ is the altitude of the nominal peak of the averaging kernel function and the A matrix $(p \times p)$ is computed as

$\mathbf{A}=\mathbf{S}_{a} \mathbf{K}^{T}\left[\mathbf{K S}_{a} \mathbf{K}^{T}+\mathbf{S}_{\varepsilon}\right]^{-1} \mathbf{K}$.

The measurement response $w$ is given by the area of the averaging kernel functions and evaluates the relative contribution of the measurements and a priori information to the retrieved profile. Values close to one indicate that most of the information comes from the measurement and thus the retrieval is 

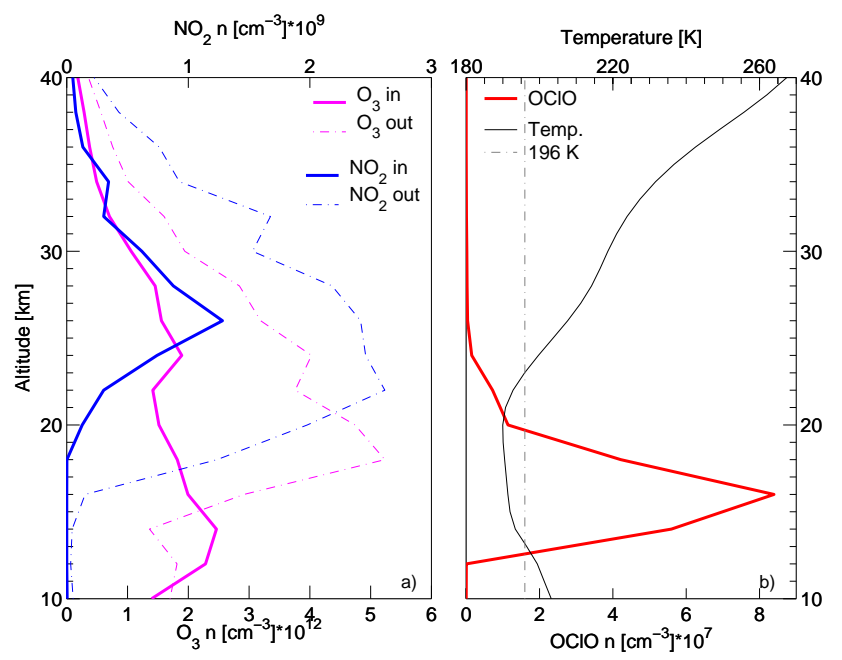

Fig. 9. (a) $\mathrm{OS} \mathrm{O}_{3}$ and $\mathrm{NO}_{2}$ number density profiles for scan 8565047 (latitude $81.7^{\circ} \mathrm{S}$, longitude $36.4^{\circ} \mathrm{E}$, SZA $92.0^{\circ}$, 18:10 LST) measured inside the polar vortex (denoted by "in" in the legend), and for scan 8565051 (latitude $60.5^{\circ} \mathrm{S}$, longitude $31.3^{\circ} \mathrm{E}$, SZA $91.5^{\circ}, 17: 57 \mathrm{LST}$ ) measured in mid-latitude air (denoted by "out" in the legend). (b) OS OClO number density and ECMWF temperature profiles for scan 8565047 .

considered to be efficient. In this study, an efficient retrieval is chosen to be characterized by $w$ larger than 0.7 .

The total retrieved error covariance is obtained by adding the covariance matrices of four error sources: smoothing error, retrieval noise, forward model error, and forward model error (Rodgers, 2000). However, the estimation of the forward model and forward model parameter errors is not carried out in this work. Thus, the total retrieval error covariance is estimated as the sum of the covariance matrices of the retrieval noise $\mathbf{S}_{m}$ and smoothing error $\mathbf{S}_{s}$, which is equivalent to the covariance matrix of the solution $\hat{\mathbf{S}}$.

Figure 8 illustrates the $\mathrm{OClO}$ averaging kernel functions, measurement response, spread, retrieval noise and smoothing error for an OSIRIS Antarctic limb scan. Between 14 and $22 \mathrm{~km}$ altitude, the averaging kernel functions peak at their corresponding altitude. This is consistent with the small smoothing error and low a priori contamination observed at the same altitudes. Hence, the vertical resolution approximates well the retrieval grid of $2 \mathrm{~km}$ for this altitude range. The averaging kernels for the 10 and $12 \mathrm{~km}$ levels have a broad peak at the wrong altitude $(14 \mathrm{~km})$. The measurements thus contain little useful information on these levels as indicated by measurement response values below 0.7. All of the averaging kernels above $22 \mathrm{~km}$ have broad peaks at $22 \mathrm{~km}$ altitude yielding large values of spread and smoothing error and low measurement response. As a result, the retrieval error (denoted by $S$ ) increases quickly with altitude for these layers. The altitude of good measurement sensitivity ( $w>0.7$ ) lies between 14 and $22 \mathrm{~km}$ for the $\mathrm{OClO}$ re- trievals. In this altitude range, the retrieval noise varies from $25 \%$ to $47 \%$ with a $2-4 \mathrm{~km}$ altitude resolution.

\section{Results and conclusions}

Several difficulties arise when trying to validate the $\mathrm{OClO}$ vertical profiles. As noted above, very few measurements of stratospheric $\mathrm{OClO}$ profiles exist, and the high photolysis rate that prevents the build-up of appreciable concentrations of $\mathrm{OClO}$ during daylight has meant that most measurements of $\mathrm{OClO}$ are performed during twilight and at night. Also, OSIRIS measurements are carried out only close to the terminator when the chlorine system is not in a steady state. As a consequence, comparisons are very sensitive to differences in time, location, and viewing geometry. Thus, direct comparisons with independent observations are difficult and have not been carried out in this study.

In order to assess whether the retrieval method is appropriate and produces reasonable results, the computed $\mathrm{OClO}$ number density profiles are tested in two ways: a) comparison to $\mathrm{OClO}$ vertical profiles measured in past Arctic balloon campaigns, and b) interpretation of the OS OClO abundances with respect to the atmospheric conditions in the lower stratosphere.

As already mentioned, a few OClO vertical profiles have been measured with other instruments inside the polar vortex area. Table 8 summarizes the peak value and corresponding altitude, location, date and time of the OClO measurements reported by Pommereau and Piquard (1994), Renard et al. (1997), Rivière et al. (2003), and for twilight evening OS OClO profiles along orbit 8565 (Fig. 11c). The maximum value reported by Rivière et al. (2003) in volume mixing ratio as a function of pressure has been converted to number density as a function of altitude by using the temperature and pressure measured in situ during the ascension of the balloon (E. D. Rivière, private communication). The peak values of the OS OClO number density profiles are larger than the peak value detected by Pommereau and Piquard (1994) inside the Arctic polar vortex at twilight. This is consistent with the larger OClO column found above Antarctica where the polar vortex is more persistent and colder, allowing the formation of PSCs over a longer period of time (e.g. Miller et al., 1999). Nighttime OClO abundances are higher than twilight measurements since photolysis is the main destruction mechanism for this species (e.g. Wahner et al., 1989). This is coherent with the lower OClO peak value observed by Pommereau and Piquard (1994) compared to the maximum values retrieved by Renard et al. (1997) and Rivière et al. (2003) in the Arctic region. However, no conclusion can be drawn on the relation between these OS OClO carried out in the austral polar region at evening twilight and Arctic observations performed at night.

Figure 9 depicts the $\mathrm{OS}_{3}$ and $\mathrm{NO}_{2}$ concentrations retrieved following Haley et al. (2004) - for two scans, 
Table 8. Observations of maximum OClO vertical concentrations. OS profiles are reported for scans 8565046 to 8565050 , indicating minimum and maximum peak values, location of the first (8565046) and last (8565050) scans, and mean values of the altitude peak concentration and SZA.

\begin{tabular}{llllll}
\hline Source & Alt. $[\mathrm{km}]$ & $n\left[\mathrm{~cm}^{-3}\right]$ & Location & Date & Time \\
\hline Pommereau \& Piquard, 1994 & 21 & $1.4 \times 10^{7}$ & $68^{\circ} \mathrm{N}, 20^{\circ} \mathrm{E}$ & $16 \mathrm{Jan}$ 92 & evening twilight, SZA 93 \\
Renard et al., 1997 & 19 & $8.7 \times 10^{7}$ & $68^{\circ} \mathrm{N}, 20^{\circ} \mathrm{E}$ & 10 Feb 95 & night \\
Rivière et al., 2003 & 18 & $8.7 \times 10^{7}$ & $68^{\circ} \mathrm{N}, 22^{\circ} \mathrm{E}$ & 23 Jan 00 & night \\
OSIRIS & 16 & $7.6 \times 10^{7}$ & $87^{\circ} \mathrm{S}, 48^{\circ} \mathrm{E}$ & $19 \mathrm{Sep} 02$ & evening twilight, SZA 92 \\
& & $9.2 \times 10^{7}$ & $66^{\circ} \mathrm{S}, 32^{\circ} \mathrm{E}$ & & \\
\hline
\end{tabular}

one inside the polar vortex area and the other one measured in mid-latitude air. The edge of the polar vortex (shown in Fig. 10, right panel) was defined, according to Braathen et al. (1994), as the potential vorticity isoline of $-48 \times 10^{-6} \mathrm{~K} \mathrm{~m}^{2} \mathrm{~kg}^{-1} \mathrm{~s}^{-1}$ at the $475 \mathrm{~K}$ isentropic level (ECMWF data). Figure 9 also displays the OS OClO and ECMWF temperature profiles for the vortex measurement. Due to the extremely small OClO concentrations, the Antarctic vortex is not shown. Large OS OClO number densities are observed inside the polar vortex over areas where reduced $\mathrm{O}_{3}$ and $\mathrm{NO}_{2}$ number densities are found. Low $\mathrm{NO}_{2}$ concentrations in the ozone "hole" area are expected due to denitrification and denoxification processes that remove and sequester reactive nitrogen compounds. Temperatures below the threshold of the PSC formation (typically $<196 \mathrm{~K}$ ) are observed between 13 and $23 \mathrm{~km}$ of altitude where the largest $\mathrm{OClO}$ concentrations are detected. Thus, the OClO profile appears to be consistent with the expected atmospheric conditions in the lower stratosphere.

To illustrate the OS capabilities of OClO detection, two figures with $\mathrm{OClO}$ profiles as well as concentrations of other related species are presented. OCIO ECD measurements along an orbit on 19 September 2002 are shown in Fig. 10 (top panel) together with two number density profiles (middle panel) inside the ozone "hole" area. The bottom panel depicts the Southern Hemisphere total ozone content from EP/TOMS (http://jwocky.gsfc.nasa.gov/ozone/ ozone_v8.html) for the same day. A clear core region of high $\mathrm{OClO}$ is observed in the region where the total ozone column is the lowest (i.e, $<200 \mathrm{DU}$ ). The mean OClO ECD inside the polar vortex region is statistically significantly larger than the mean OClO ECD outside the vortex at 95\% confidence level. The ECDs outside of the vortex area are extremely small and frequently negative, as noted in Sect. 3.2, due to the very low abundance of $\mathrm{OClO}$ outside of chlorine activation regions. As a result, $\mathrm{OClO}$ number density retrievals are limited to chlorine activation regions. The morning twilight $\mathrm{OClO}$ profile (scan A) peaks at $16 \mathrm{~km}$ with an estimated retrieval error of $31 \%$ whereas the evening twilight profile (scan B) peaks at $16 \mathrm{~km}$ with an estimated retrieval error of $40 \%$. The horizontal extent of these scans between 10 and $25 \mathrm{~km}$ height is $166.7 \mathrm{~km}$ and $152.6 \mathrm{~km}$, respectively. The evening twilight concentrations are significantly larger than the morning twilight abundances, in accordance with the results found by Solomon et al. (1990). Figure 11 displays the number density profiles of $\mathrm{O}_{3}, \mathrm{NO}_{2}, \mathrm{OClO}$, and $\mathrm{ClO}$ along the orbit for latitudes south of $40^{\circ} \mathrm{S}$. All of these measurements were performed at twilight conditions with SZA ranging from $91^{\circ}$ to $92.1^{\circ}$ when Odin was pointing off of the orbital plane into the sunlit region. $\mathrm{O}_{3}$ and $\mathrm{NO}_{2}$ profiles were derived from $\mathrm{OS}$ measurements according to Haley et al. (2004). The SMR retrieval group at Chalmers University of Technology retrieved the ClO profiles from Odin/SMR spectra (Urban et al., 2005). The white lines in the plots indicate the lowermost and uppermost altitudes of significant measurements. A large ozone depletion is mainly detected in the $15-30 \mathrm{~km}$ altitude range, associated with an important denitrification and denoxification of the lower stratosphere as shown in plots a) and b), respectively. An $\mathrm{OClO}$ enhancement is observed at the same latitudes as the ozone reduction and altitudes between 12 and $20 \mathrm{~km}$ (panel c). The sunrise $\mathrm{OClO}$ concentrations are smaller than the sunset abundances since the diurnal variation is largely driven by the diurnal cycle of its photolysis rate (Solomon et al., 1990). An area with large $\mathrm{ClO}$ concentrations is observed at altitudes below $22 \mathrm{~km}$ (panel d) but does not overlap with the enhanced $\mathrm{OClO}$ region depicted in panel c. An explanation for this disagreement could be based on the results of Sessler et al. (1995). After performing model simulations for Artic winter conditions inside the polar vortex, they concluded that $\mathrm{OClO}$ concentrations are weakly dependent on $\mathrm{ClO}$ abundances for large SZA, when the system is far from being in a steady state. The threshold SZA value was found to be $92^{\circ}$ in that study, and depends on the altitude and location of the measurements.

In summary, an algorithm for retrieving stratospheric OClO profiles from limb-scattered sunlight radiances has been described and applied to OS measurements. OClO profiles were retrieved inside the Antarctic polar vortex region with a measurement response above 0.7 and a vertical resolution of $2-5 \mathrm{~km}$ in the altitude range $14-22 \mathrm{~km}$. The estimated retrieval error is better than $50 \%$ at the peak of these profiles. This unique data set of $\mathrm{OClO}$ profiles is very promising for the study of the seasonal and interannual variability of this species, for inter-hemispheric comparisons, and for studies 

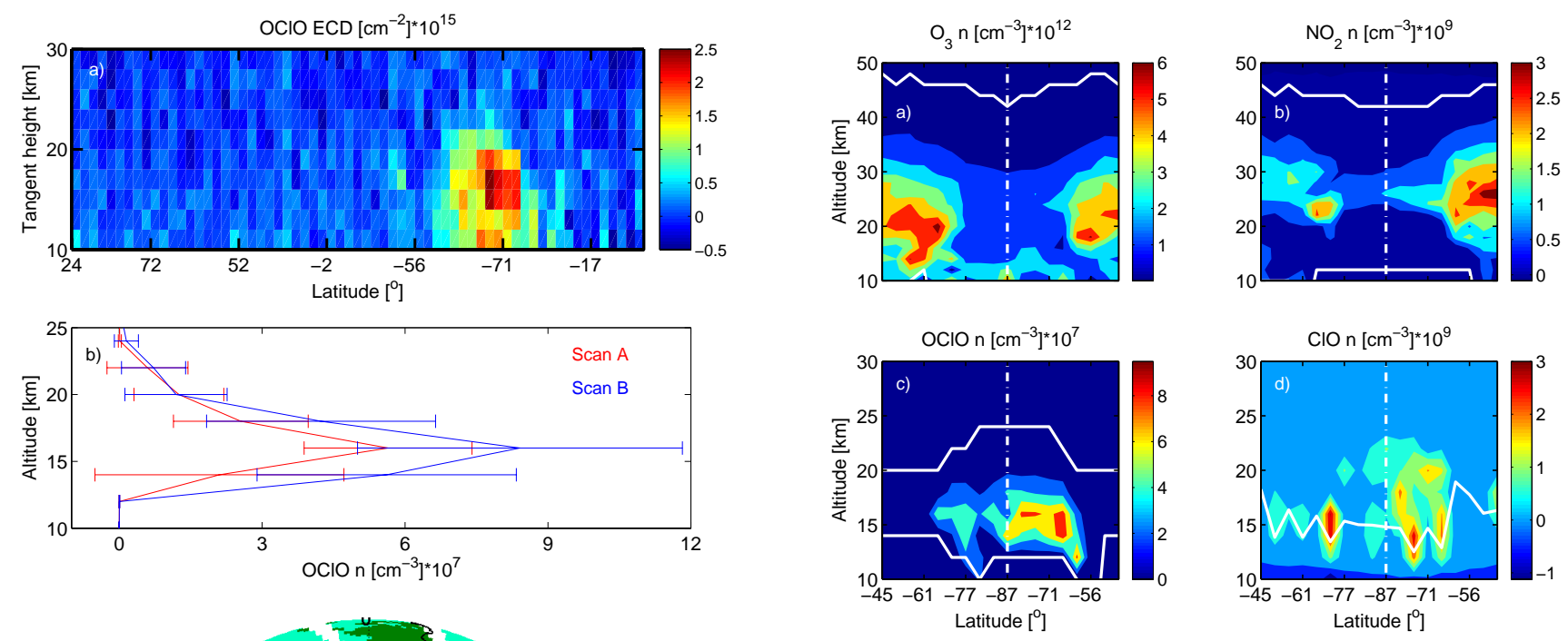

Fig. 11. Retrieved number density profiles of (a) $\mathrm{OS} \mathrm{O}_{3}$, (b) $\mathrm{OS}$ $\mathrm{NO}_{2}$, (c) OS OClO, and (d) SMR ClO along Odin orbit 8565 for latitudes southward of $40^{\circ} \mathrm{S}$. The white lines in each plot represent the lowermost and uppermost altitudes of significant measurements $(w>0.7)$. The dashed-dotted line in each plot separates the sunrise (left) and sunset (right) measurements.

Acknowledgements. The first author thanks Patrick Eriksson for helpful comments to set up the a priori constraint in the $\mathrm{OClO}$ retrievals. We also thank the SMR retrieval group at Chalmers University of Technology and the Odin/OSIRIS team for making the $\mathrm{ClO}$ vertical profiles and OSIRIS level 1 data available, respectively. The two anonymous referees are acknowledged for their comments that greatly helped to improve the quality of this manuscript. This work was supported by the Swedish National Space Board, Chalmers University of Technology, and the Canadian Space Agency. Odin is a Swedish-led satellite project funded jointly by Sweden (SNSB), Canada (CSA), Finland (Tekes) and France (CNES).

10. Top panel: Latitude vs. tangent height representation OClO ECD along Odin orbit 8565 on 19 September 2002. Middle panel: OClO number density profiles for scans A (number 8565045 , latitude $87.6^{\circ} \mathrm{S}$, longitude $165.0^{\circ} \mathrm{W}$, SZA $92.1^{\circ}, 4: 43 \mathrm{LST}$ ) and $\mathrm{B}$ (number 8565047 , latitude $81.7^{\circ} \mathrm{S}$, longitude $36.4^{\circ} \mathrm{E}$, SZA $92.0^{\circ}$, 18:10 LST) with their corresponding retrieval error. Bottom panel: Austral total O3 from EP/TOMS for the same day. The thick black line represents the OS tangent point path for orbit 8565, A and B indicate the average location of scans $\mathrm{A}$ and $\mathrm{B}$, and the arrow indicates the direction of Odin's movement. The ECMWF potential vorticity isoline of $-48 \times 10^{-6} \mathrm{~K} \mathrm{~m}^{2} \mathrm{~kg}^{-1} \mathrm{~s}^{-1}$ at the $475 \mathrm{~K}$ isentropic level for the same day at 12:00 UTC is also shown (dash-dotted line). Note that Odin was pointing off of the orbit plane to achieve a better coverage.

of the OClO-ClO relation in twilight conditions. Further characterization of the forward model and forward model parameter errors has to be carried out. Also, further comparisons with other $\mathrm{OClO}$ measurements are desirable for data validation.

Edited by: A. Richter

\section{References}

Aruga, T. and Heath, D. F.: Determination of vertical ozone distributions by spacecraft measurements using a limb-scan technique, Appl. Opt., 21(16), 3047-3054, 1982.

Backus, G. E. and Gilbert, J. F.: Uniqueness in the inversion of inaccurate gross Earth data, Philos. Trans. R. Soc. London, Ser. A, 266, 123-192, 1970.

Bates, D. R.: Rayleigh scattering by air, Planet. Space Sci., 32(6), 785-790, 1984.

Bertaux, J., Mégie, G., Widemann, T., Chassefière, E., Pellinen, R., Kyrölä, E., Korpela, S., and Simon, P.: Monitoring of ozone trend by stellar occultations: The GOMOS instrument, Adv. Space Res., 11(3), 237-242, 1991.

Bogumil, K., Orphal, J., Homann, T., et al.: Measurements of molecular absorption spectra with the SCIAMACHY pre- 
flight model: Instrument characterization and reference data for atmospheric remote-sensing in the $230-2380 \mathrm{~nm}$ region, J. Photochem. Photobiol. A: Chem, 157, 167-184, doi:.10.1016/S1010-6030(3)00062-5, 2003.

Bovensmann, H., Burrows, J. P., Buchwitz, M., Frerick, J., Noël, S., Rozanov, V. V., Chance, K. V., and Goede, A. P. H.: SCIAMACHY: Mission objectives and measurement modes, J. Atmos. Sci., 56(2), 127-150, 1999.

Braathen., G. O., Rummukainen, M., Kyrö, E., Schmidt, U., Dahlback, A., Jørgersen, T. S., Fabian, R., Rudakov, V. V., Gil, M., and Borchers, R.: Temporal development of ozone within the Arctic vortex during the winter of 1991/92, Geophys. Res. Lett., 21(13), 1407-1410, 1994.

Brandtjen, R., Klüpfel, T., and Perner, D.: Airborne measurements during the European Arctic Stratospheric Ozone Experiment: Observation of OClO, Geophys. Res. Lett., 21(13), 1363-1366, 1994.

Farman, J. C., Gardiner, G., and Shanklin, J. D.: Large ozone losses of total ozone in Antarctica reveal seasonal $\mathrm{ClO}_{\mathrm{x}} / \mathrm{NO}_{\mathrm{x}}$ interaction, Nature, 315, 207-210, 1985.

Flittner, D. E., Bhartia, P. K, and Herman, B. M., $\mathrm{O}_{3}$ profiles retrieved from limb scatter measurements: Theory, Geophys. Res. Lett., 27(17), 2601-2604, 2000.

Frisk, U., Hagström, M., Ala-Laurinaho, S., et al.: The Odin satellite I: Radiometer design and test, Astron. Astrophys., 402(3), L27-L34, doi:10.1051/0004-6361:20030335, 2003.

Greenblatt, G. D., Orlando, J. J., Burkholder, J. B., and Ravinshankara, A. R.: Absorption measurements of oxygen between 300 and 1140 nm, J. Geophys. Res., 95(D11), 18 577-18 583, 1990.

Griffioen, E. and Oikarinen, L.: LIMBTRAN: A pseudo threedimensional radiative transfer model for the limb-viewing imager OSIRIS on the Odin satellite, J. Geophys. Res., 105(D24), 29717-29730, 2000.

Haley, C. S., Brohede, S. M., Sioris, C. E., Griffioen, E., Murtagh, D. P., McDade, I. C., Eriksson, P., Llewellyn, E. J., Bazureau, A., and Goutail, F.: Retrieval of stratospheric $\mathrm{O}_{3}$ and $\mathrm{NO}_{2}$ profiles from Odin Optical Spectrograph and Infrared Imager System (OSIRIS) limb-scattered sunlight measurements, J. Geophys. Res., 109, D16303, doi:10.1029/2004JD004588, 2004.

Kaiser, J. W.: Atmospheric parameter retrieval from UV-vis-NIR limb scattering measurements, Ph. D. thesis, Inst. of Environ. Phys.-Inst. of Remote Sens., Univ. of Bremen, Bremen, Germany, 2001.

Koelemeijer, R. B. A., de Haan, J. F., and Stammes, P.: A database of spectral surface reflectivity in the range $335-772 \mathrm{~nm}$ derived from 5.5 years of GOME observations, J. Geophys. Res., 108(D2), 4070, doi:10.1029/2002JD002429, 2003.

Kromminga, H., Orphal, J., Spietz, P., Voigt, S., and Burrows, J. P.: New measurements of $\mathrm{OClO}$ absorption cross sections in the 325-435 nm and their temperature dependence between 213-293 K, J. Photochem. Photobiol. A.: Chem, 157, 149-160, 2003.

Lefèvre, F., Brasseur, G. P., Folkins, I., Smith, A. K., and Simon, P.: Chemistry of the 1991-1992 stratospheric winter: Threedimensional model simulations, J. Geophys. Res., 99(D4), 81838195, 1994.

Lefèvre, F., Figarol, K., Carslaw, S., and Peter, T.: The 1997 Arctic ozone depletion quantified from three-dimensional model simulations, Geophys. Res. Lett., 25, 2425-2428, 1998.
Levenberg, K.: A method for the solution of certain problems in least-squares, Q. Appl. Math., 2, 164-168, 1944.

Li, D. and Shine, K. P.: A 4-dimensional ozone climatology for UGAMP models, UGAMP internal report 35, UK Univ. Global Atmos. Modell. Programme, Reading, 1995.

Llewellyn, E. J., Lloyd, N. D., Degenstein, D. A., et al.: The OSIRIS instrument on the Odin spacecraft, Can. J. Phys., 82(6), 411-422, doi:10.1139/P04-005, 2004.

Marquardt, D.: An algorithm for least-squares estimation on nonlinear parameters, SIAM J. Appl. Math., 11, 431-441, 1963.

McCormick, M. P., Chu, W. P., Zawodny, J. M., Mauldin III, L. E., and McMaster, L. R.: Stratospheric Aerosol and Gas Experiment III (SAGE III) aerosol and trace gas measurements for Earth Observing System (EOS), Proc. SPIE Int. Soc. Opt. Eng., 1491, 125-141, 1991.

McCormick, M. P., Wang, P. H., and Pitts, M. C.: Background stratospheric aerosol and polar stratospheric cloud reference models, Adv. Space Res., 18(9-10), 155-177, 1996.

McDade, I. C., Strong, K., Halley, C. S., Stegman, J., Murtagh, D. P., and Llewellyn, E. J.: A method for recovering stratospheric minor species densities from the Odin/OSIRIS scattered-sunlight measurements, Can. J. Phys., 80(4), 395-408, 2002.

McLinden, C. A., Olsen, S., Hannegan, B., Wild, O., Prather, M. J., and Sundet, J.: Stratospheric ozone in 3-D models: A simple chemistry and the cross-tropopause flux, J. Geophys. Res., 105(D11), 14 653-14 665, 2000.

McLinden, C. A., McConnell, J. C., Strong, K., McDade, I. C., Gattinger, R. L., King, R. Solheim, B., Llewellyn, E. J., and Evans, W. F. J.: The impact of the OSIRIS grating efficiency on radiance and trace-gas retrievals, Can. J. Phys., 80(4), 469-481, 2002.

Miller, H. L., Saunders, R. W., and Solomon, S.: Observations and interpretation of column OClO seasonal cycles at two polar sites, J. Geophys. Res., 104(D15), 18 769-18 783, 1999.

Murtagh, D., Frisk, U., Merino, F., et al.: An overview of the Odin atmospheric mission, Can. J. Phys., 80(4), 309-319, 2002.

Noxon, J. F.: Nitrogen dioxide in the stratosphere and troposphere measured by ground-based absorption spectroscopy, Science, 189, 547-549, 1975.

Noxon, J. F., Whipple, E. C., and Hyde, R. S.: Stratospheric $\mathrm{NO}_{2} \mathrm{I}$. Observational method and behavior at mid-latitude, J. Geophys. Res., 28(8), 5047-5065, 1979.

Orphal, J., A critical review of the absorption cross-sections of $\mathrm{O}_{3}$ and $\mathrm{NO}_{2}$ in the $240-740 \mathrm{~nm}$ region, J. Photochem. Photobiol. A: Chem., 157(2-3), 185-209, doi:10.1016/S1010-6030(03)000613, 2003.

Payan, S., Camy-Peyret, C., Jeseck, P., et al., HALOMAX results on reservoir and active chlorine species: Ballon measurements and comparison with 3-D chemical transport model, stratospheric ozone 1999, in Proceedings of the fifth European symposium, 27 September to 1 October 1999, Saint Jean de Luz, France, 1999.

Perner, D., Klüpfel, T., Parchatka, U., Roth, A., and Jørgensen, T.: Ground-based UV-VIS spectroscopy: Diurnal OClO profiles during January 1990 above Søndre Strømfjord, Greenland, Geophys. Res. Lett., 18(4), 787-790, 1991.

Perner, D., Roth, A., and Klüpfel, T.: Groundbased measurements of stratospheric $\mathrm{OClO}, \mathrm{NO}_{2}$, and $\mathrm{O}_{3}$ at Søndre Strømfjord in winter 1991/92, Geophys. Res. Lett., 21(13), 1367-1370, 1994.

Platt, U., Perner, D., and Pätz, H. W.: Simultaneous measurement of atmospheric $\mathrm{CH}_{2} \mathrm{O}, \mathrm{O}_{3}$ and $\mathrm{NO}_{2}$ by differential optical ab- 
sorption, J. Geophys. Res., 84(10), 6329-6335, 1979.

Platt, U.: Differential optical absorption spectroscopy (DOAS), in: Air Monitoring by Spectroscopic Techniques, edited by: M. Sigrist, John Wiley, Hoboken, N.J., 27-84 pp., 1994.

Pommereau, J. P. and Piquard, J.: Observations of the vertical distribution of stratospheric OClO, Geophys. Res. Lett., 21(13), 12311234, 1994.

Prather, M. and Jaffe, A. H.: Global impact of the Antarctic ozone hole: Chemical propagation, J. Geophys. Res., 95(D4), 34733492, 1990.

Renard, J. B., Lefèvre, F., Pirre, M., Robert, C., and Huguenin, D.: Vertical profile of night-time stratospheric OClO, J. Atmos. Chem., 26, 65-76, 1997.

Rivière, E. D., Pirre, M., Berthet, G., Renard, J.-B., Taupin, F. G., Huret, N., and Chartier, M.: On the interaction between nitrogen and halogen species in the Arctic polar vortex during THESEO and THESEO 2000, J. Geophys. Res., 108(D5), 8311, doi:10.1029/2002JD002087, 2003.

Rodgers, C. D.: Inverse Methods for Atmospheric Sounding: Theory and Practice, 1st ed., World Sci., River Edge, N. J., 238 pp., 2000.

Rusch, D. W., Mount, G. H., Barth, C. A., Thomas, R. J., and Callan, M. T.: Solar Mesospheric Explorer ultraviolet spectrometer: Measurements of ozone in the 1.0-0.1 mbar region, J. Geophys. Res., 89(D7), 11 677-11687, 1984.

Sander, S. P., Friedl, R. R., DeMore, W. B., et al.: Chemical kinetics and photochemical data for use in stratospheric modeling, Evaluation number 13, JPL Publication 00-03, 2000.

Sanders, R. W., Solomon, S., Carroll, M. A., and Schmeltekopf, A. L.: Visible and near-ultraviolet spectroscopy at McMurdo station, Antarctica, 4. Overview and daily measurements of $\mathrm{NO}_{2}$, $\mathrm{O}_{3}$, and OClO during 1987, J. Geophys. Res., 94(D9), $11381-$ $11391,1989$.

Schiller, C., Wahner, A., Platt, U., Dorn, H., Callies, J., and Ehhalt, D. H.: Near UV atmospheric absorption measurements of column abundances during airborne Arctic Stratospheric Expedition, January-February 1989: 2. OClO observations, Geophys. Res. Lett., 17(4), 501-504, 1990.

Sessler, J., Chipperfield, M. P., Pyle, J. A., and Tuomi, R.: Stratospheric OClO measurements as a poor quantitative indicator of chlorine activation, Geophys. Res. Lett., 22(6), 687-690, 1995.

Sioris, C. E., Evans, W. F. J., Gattinger, R. L., McDade, I. C., Degenstein, D. A., and Llewellyn, E. J.: Ground-based Ringeffect measurements with the OSIRIS development model, Can. J. Phys., 80(4), 483-491, 2002.

Sioris, C. E., Haley, C. S., McLinden, et al.: Stratospheric profiles of nitrogen dioxide observed by Optical Spectrograph and Infrared Imager System on the Odin satellite, J. Geophys. Res., 108(D7), 4215, doi:10.1029/2002JD002672, 2003.
Solomon, S., Mount, G. H., Sanders, R. W., and Schmeltekopf, A. L.: Visible spectroscopy at McMurdo Station, Antarctica, 2. Observations of OClO, J. Geophys. Res., 92(D7), 8329-8338, 1987.

Solomon, S., Sanders, R. W., and Miller, H. L.: Visible and near-ultraviolet spectroscopy at McMurdo Station, Antarctica 7. OClO diurnal photochemistry and implications for ozone destruction, J. Geophys. Res., 95(D9), 13 807-13 817, 1990.

Solomon, S.: Stratospheric ozone depletion: A review of concepts and history, Rev. Geophys., 37(3), 275-316, 1999.

Strong, K., Joseph, B., Dosanjh, R., McDade, I., McLinden, C., McConnell, J., Stegman, J., Murtagh, D., and Llewellyn, E. J.: Retrieval of vertical concentration profiles from OSIRIS UV-visible limb spectra, Can. J. Phys., 80(4), 409-434, 2002.

Urban, J., Lautié, N., Le Flochmoën, E., et al.: Odin/SMR limb observations of stratospheric trace gases: Level 2 processing of $\mathrm{ClO}, \mathrm{N}_{2} \mathrm{O}, \mathrm{HNO}_{3}$, and $\mathrm{O}_{3}$, J. Geophys. Res., 110, D14307, doi:10.1029/2004JD005741, 2005.

Van Roozendael, M., Hermans, C., Kabbadj, Y., Lambert, J.-C., Vandaele, A.-C., Simon, P. C., Carleer, M., Guilmot, J.-M., and Colin, R.: Ground-based measurements of stratospheric $\mathrm{OClO}, \mathrm{NO}_{2}$, and $\mathrm{O}_{3}$ at Harestua, Norway $\left(60^{\circ} \mathrm{N}, 10^{\circ} \mathrm{E}\right)$ during SESAME, in Proceedings of 12th ESA Symposium on Rocket and Balloon Programmes \& Related Research, Lillehammer, Norway, 29 May-1 June 1995, Eur. Space Agency Spec. Publ., ESA, SP-370, 305-310, 1995.

Vandaele, A., Hermans, C., Simon, P., Carleer, M., Colin, R., Fally, S., Mérienne, M. F., Jenouvrier, A., and Coquart, B.: Measurements of the $\mathrm{NO}_{2}$ absorption cross section from $42000 \mathrm{~cm}^{-1}$ to $10000 \mathrm{~cm}^{-1}(283-1000 \mathrm{~nm})$ at $220 \mathrm{~K}$ and $294 \mathrm{~K}$, J. Quant. Spectrosc. Radiat. Transfer, 59(3-5), 171-184, 1998.

Wagner, T., Leue, C., Pfeilsticker, K., and Platt, U.: Monitoring of the stratospheric chlorine activation by Global Ozone Monitoring Experiment (GOME) OClO measurements in the austral and boreal winters 1995 through 1999, J. Geophys. Res., 106(D5), 4971-4986, 2001.

Wahner, A., Jakoubek, R. O., Mount, G. H., Ravishankara, A. R., and Schmeltekopf, A. L.: Remote sensing observations of nighttime OClO column during the Airborne Antarctic Ozone Experiment, September 8, 1987, J. Geophys. Res., 94(D9), 11405 $11411,1989$.

Wilmouth, D. M., Hanisco, T. F., Donahue, N. M., and Anderson, J. G.: Fourier transform ultraviolet spectroscopy of the $\mathrm{A}\left({ }^{2} \prod_{3 / 2}\right)$ $\leftarrow \mathrm{X}\left({ }^{2} \prod_{3 / 2}\right)$ transition of BrO, J. Phys. Chem. A, 103, 89358945, 1999.

WMO (World Meteorological Organization), Scientific Assessment of Ozone Depletion: 2002, Global Ozone Research and Monitoring Project, Report No. 47, 498 pp., Geneva, 2003. 